\title{
ENSO, Pacific Decadal Variability, and U.S. Summertime Precipitation, Drought, and Stream Flow
}

\author{
M. BARLOW,* S. NigAM, AND E. H. BERBERY \\ Department of Meteorology, University of Maryland at College Park, College Park, Maryland
}

(Manuscript received 10 May 1999, in final form 25 February 2000)

\begin{abstract}
The relationship between the three primary modes of Pacific sea surface temperature (SST) variability-the El Niño-Southern Oscillation (ENSO), the Pacific decadal oscillation, and the North Pacific mode-and U.S. warm season hydroclimate is examined. In addition to precipitation, drought and stream flow data are analyzed to provide a comprehensive picture of the lower-frequency components of hydrologic variability.

ENSO and the two decadal modes are extracted from a single unfiltered analysis, allowing a direct intercomparison of the modal structures and continental linkages. Both decadal modes have signals in the North Pacific, but the North Pacific mode captures most of the local variability. A summertime U.S. hydroclimatic signal is associated with all three SST modes, with the linkages of the two decadal modes comparable in strength to that of ENSO.

The three SST variability modes also appear to play a significant role in long-term U.S. drought events. In particular, the northeastern drought of the 1960s is shown to be closely linked to the North Pacific mode. Concurrent with the drought were large positive SST anomalies in the North Pacific, quite similar in structure to the North Pacific mode, and an example of a physical realization of the mode. Correspondingly, the 196266 drought pattern had considerable similarity to the drought regression associated with the North Pacific mode. Analysis of upper-level stationary wave activity during the drought period shows a flux emanating from the North Pacific and propagating over the United States. The near-equivalent-barotropic circulation anomalies originating in the North Pacific culminate in a cyclonic circulation over the East Coast that, at low levels, opposes the climatological inflow of moisture in an arc over the continent from the Gulf Coast to the Northeast, consistent with the observed drought.
\end{abstract}

\section{Introduction}

The notable impacts of ENSO on global climate [see, e.g., the review by Rasmusson (1991)], including significant U.S. connections (Ropelewski and Halpert 1986), have drawn a great deal of attention to Pacific variability and related atmospheric anomalies. In addition to ENSO, there is now considerable evidence for two other important modes of Pacific variability with significant teleconnections: a mode with decadal-scale time variations, spanning both the tropical and extratropical Pacific (Nitta and Yamada 1989; Zhang et al. 1997; Mantua et al. 1997; Zhang et al. 1998; Enfield and Mestas-Nuñez 1999); and a mode (or modes) in the North Pacific, with both strong decadal-scale and in-

* Current affiliation: International Research Institute for Climate Prediction, Columbia University, Palisades, New York.

Corresponding author address: Mathew A. Barlow, International Research Institute, Lamont-Doherty Earth Observatory, Palisades, NY 10964-8000.

E-mail: mattb@iri.ldeo.columbia.edu terseasonal-interannual variability (Weare et al. 1976; Davis 1976; Tanimoto et al. 1993; Deser and Blackmon 1995; Nakamura et al. 1997; Mestas-Nuñez and Enfield 1999).

Various aspects of the connections between U.S. precipitation and ENSO have been examined in several studies (Douglas and Englehart 1981; Ropelewski and Halpert 1986; Richman et al. 1991; Montroy 1997; Montroy et al. 1998), although focus on the summer season has not been common, with a few exceptions (Ting and Wang 1997; Higgins et al. 1999). The relationship between ENSO and other elements of the U.S. hydroclimate, including drought, stream flow, and snow water content, has also been analyzed (Redmon and Koch 1991; Cayan and Webb 1992; Piechota and Dracup 1996) but, again, with little emphasis on summer.

Links between decadal-scale Pacific sea surface temperature (SST) variability and North American climate are also beginning to be explored. Ting and Wang (1997) analyzed coupled variability between U.S. summertime precipitation and Pacific SST variability. While the first coupled mode was associated with ENSO, the second coupled mode exhibited decadal-scale variations and linked U.S. summertime precipitation anomalies with 
SST anomalies in the North Pacific Ocean. ${ }^{1}$ Livezey and Smith (1999) have shown a link between decadal-scale U.S. surface temperature and 700-hPa height variations and a pan-Pacific SST pattern-an SST pattern with significant values over large regions of both the Tropics and extratropics. Analysis of annual precipitation anomalies in the western United States has also identified decadal-scale variations associated with a pan-Pacific pattern of SST anomalies (Cayan et al. 1998). In addition to the North Pacific-United States connection documented by Ting and Wang (1997), North Pacific variability has also been linked, in the winter, to the Pacific-North American (PNA) atmospheric pattern (Deser and Blackmon 1995), which substantially impacts U.S. winter weather (e.g., Wallace and Gutzler 1981). The Pacific decadal variability also appears to affect U.S. wintertime climate through modulation of the ENSO relationship (Gershunov and Barnett 1998).

Although the evidence for a relationship between U.S. climate anomalies and multiple modes of Pacific variability is growing, the structure of the SST modes (and their teleconnections) identified in these different studies remains to be robustly characterized. The identified modes may be broadly grouped into three categories: ENSO; a pan-Pacific SST pattern with decadal-scale variations, consisting of an out-of-phase relationship between the central and eastern equatorial Pacific and the central North Pacific; and a pattern (or patterns) restricted to the North Pacific, with both decadal-scale and higher-frequency variations. Between different studies, however, the boundaries between the categories are blurred; the first SST mode (in terms of explained variance) of some studies (Nitta and Yamada 1989; Ting and Wang 1997) has similarities to both the ENSO mode in other analyses (e.g., Zhang et al. 1996) and the panPacific decadal mode (Mantua et al. 1997; Zhang et al. 1997), while some realizations of the pan-Pacific mode (Mantua et al. 1997), in turn, look similar to the North Pacific mode (Deser and Blackmon 1995). Some studies show results only for the North Pacific (Tanimoto et al. 1993), so it is not possible to discern whether the derived mode is limited to the region or is part of the pan-Pacific mode. Furthermore, the North Pacific SST variability described by the second coupled mode in Ting and Wang (1997) is structurally different from North Pacific variability analysis based on SST alone (e.g., Tanimoto et al. 1993). Finally, aspects of the derived time evolutions, such as the climate shift in 1976/77, are associated with different modes in these studies: variously, ENSO (Deser and Blackmon 1995; Nitta and Yamada 1989), the pan-Pacific mode (Mantua et al. 1997; Zhang et al. 1998), or the North Pacific mode (Tanimoto et al. 1993).

In addition to the lack of clear distinction among the

\footnotetext{
${ }^{1}$ Although, the pattern of SST anomalies was different than that extracted from the SST-only based analyses mentioned at the beginning of this section.
}

various Pacific SST modes, aspects of the linkages during summer, the primary growing season, have remained largely unexplored, particularly from the hydrologic viewpoint (e.g., precipitation, drought, and stream flow considered together).

Accordingly, the current study has two principal objectives: first, to differentiate among the structures of the robust modes of Pacific SST variability; and second, to comprehensively evaluate their impact on warm season U.S. hydroclimate, by examining linkages with precipitation, drought, and stream flow.

The primary SST analysis is based on the monthly anomalies during 1945-93. Because this observationally rich period provides only four to five possible realizations for decadal-scale variability, the short-term SST analysis is supplemented by a variability analysis of the 1900-91 SST record. The hydroclimatic data analyzed are precipitation (1950-85), stream flow (1950-85), and the Palmer drought severity index (PDSI; 1945-93). Atmospheric circulation data are also examined, from the National Centers for Environmental Prediction-National Center for Atmospheric Research (NCEP-NCAR) reanalysis (1958-93). The datasets are described in section 2.

The first three modes of Pacific SST variability (ENSO, the pan-Pacific decadal mode, and the North Pacific mode) are considered in section 3. These modes are extracted from the monthly anomalies via rotated principal component analysis (RPCA), with the analysis specifically designed for accurate differentiation among modes (rotation of modes, large domain, unfiltered data, all months of the year included). This approach objectively extracts all three modes from the same analysis, without recourse to time filtering.

The linkages to U.S. precipitation, drought, and stream flow are obtained from regression against the principal components of these modes, and the June, July, and August regressions are described in section 4. This hydrologic analysis is complemented by analysis of the corresponding upper-level streamfunction anomalies and stationary wave activity in the 1958-93 NCEPNCAR reanalysis data. The atmospheric analysis shows a coherent flux of stationary wave activity from the eastern North Pacific for both decadal modes, extending across the United States.

Having examined these general relationships, specific long-term drought episodes are considered in section 5 , to assess the importance of the three SST modes during the central U.S. drought of the 1950s and the northeastern drought of the 1960s. The SST modes are active in both periods, particularly the North Pacific mode during the 1960s drought, and the observed drought patterns are similar to the patterns generally associated with the SST modes.

The final analysis segment, section 6, is a sensitivity analysis of the extraction of the SST modes. The three modes are also extracted from long-term (1900-91) data to assess the stability of the 1945-93 analysis, and a 
comparison is provided between the full-domain and the North Pacific basin analyses, and between rotated and unrotated results. Discussion and conclusions follow in section 7 .

\section{Data}

\section{a. Sea surface temperature}

The University of Wisconsin-Milwaukee version of the Comprehensive Ocean-Atmosphere Data Set (UWM/COADS; da Silva et al. 1994) was used as the primary dataset for SST. The COADS data has proven to be a highly useful basis for studies of SST variability (e.g., Tanimoto et al. 1993; Deser and Blackmon 1995; Zhang et al. 1996; Nakamura et al. 1997; and many others). The UWM/COADS is a revised version, at higher resolution, and with a complete set of estimates of heat, momentum, and freshwater fluxes. While the higher resolution and fluxes of these data are not capitalized on in the current analysis, the UWM revised version is used to allow compatibility with future analysis of the fluxes and higher-resolution features. The UWM/ COADS SSTs are available monthly from 1945-93, on a $1^{\circ}$ lat $\times 1^{\circ}$ long grid. The primary data concern for SSTs in this period is the spatial density of observations. Quality control consists of a statistical analysis that identifies outliers. Even in the early part of the analysis record, there are only a few $1^{\circ}$ lat $\times 1^{\circ}$ long boxes containing no observations, with some exceptions in the equatorial regions and the southeastern part of the domain. The North Pacific is the best observed area of the basin, with coverage maximizing around $30^{\circ} \mathrm{N}$. An objective, successive-correction technique was used to interpolate over areas of missing data and to remove small-scale, noisy features, essentially using the same technique as Levitus (1982). See da Silva at al. (1994) for a detailed discussion of the preparation of the data. For the current analysis, the data were interpolated to a $2^{\circ}$ lat $\times 6^{\circ}$ long grid, and all calculations were performed on an equal-area version of the grid.

In order to provide a longer-term comparison for the variability analyzed from the UWM/COADS data, the reduced-space optimal smoothing extended SST analysis of Kaplan et al. (1998) is used to analyze the variability from 1900 to 1991. The Kaplan et al. analysis is based on a combination of a least squares optimal smoother and an 80-member empirical orthogonal function reconstruction based on the 1951-91 period (Kaplan et al. 1997, 1998). The input data are monthly averaged anomalies of individual ship observations from the U.K. Meteorological Office historical sea surface temperature dataset [see Parker et al. (1994) and Folland and Parker (1995) for a discussion of systematic bias corrections] version of the Global Ocean Surface Temperature Atlas (Bottomley et al. 1990). The extended Kaplan et al. analysis uses this procedure for the 185681 period and a reconstruction, with the same 80 mem- bers, of the NCEP optimal interpolation analysis (which combines ship observations with remote sensing data; Reynolds and Smith 1994) for the post-1981 period. The Kaplan data is available monthly, on a $5^{\circ}$ lat $\times 5^{\circ}$ long grid; the period used for the current analysis is $1900-$ 91.

\section{b. Subsurface ocean temperatures}

The 1950-95 ocean reanalysis produced at the University of Maryland (Carton et al. 1999a,b) was used to provide an estimate of subsurface temperature anomalies. The ocean reanalysis procedure is similar to atmospheric reanalysis and uses an optimal interpolation scheme in conjunction with an high-resolution ocean model to assimilate a wide variety of observed data. The observed data includes temperature and salinity profiles from the World Ocean Atlas-94 [from mechanical bathythermographs, expendable bathythermographs (XBTs), conductivity-temperature-depth, and station measurements], as well as additional XBT data, sea surface temperature, surface winds, and altimetry data. Several quality control restrictions were applied in the reanalysis, with the most restrictive being comparison to climatology and tests for static stability. Spatially, data coverage closely follows ship routes and is similar to that of the COADS data. The resolution of the data is based on the ocean model grid, which expands from $0.5^{\circ}$ lat $\times 2.5^{\circ}$ long in the Tropics to $1.5^{\circ}$ lat $\times 2.5^{\circ}$ long at midlatitudes. See Carton et al. (1999a) for a full discussion of the reanalysis procedure.

\section{c. Precipitation}

The monthly precipitation values for the coterminous United States used in this study are extracted from the Global Historical Climatology Network (GHCN) dataset. This dataset was designed specifically for monitoring and detecting climate change, and has undergone many quality control tests, including visual inspection of all station time series, tests for mislabeling of times and locations, and others (Vose et al. 1992). The GHCN data combines several previously existing datasets; the bulk of the U.S. stations are from the U.S. Historical Climatology Network (HCN; Karl et al. 1990), which has extensive quality control, including corrections for bias due to change in observing times (Karl and Williams 1987). We have repeated our precipitation analysis with only the HCN stations and the results are not sensitive to the change, so we have used the additional stations in the GHCN dataset for greatest station density. From the GHCN data, we have extracted only those stations that began reporting on or before 1950, and ended reporting on or after 1985, to maintain consistent spatial coverage. The $1950-85$ period was chosen as a compromise between station density and length of record (see Fig. 1a for the resultant 1473 stations). Given the uneven distribution of stations, all computations and 


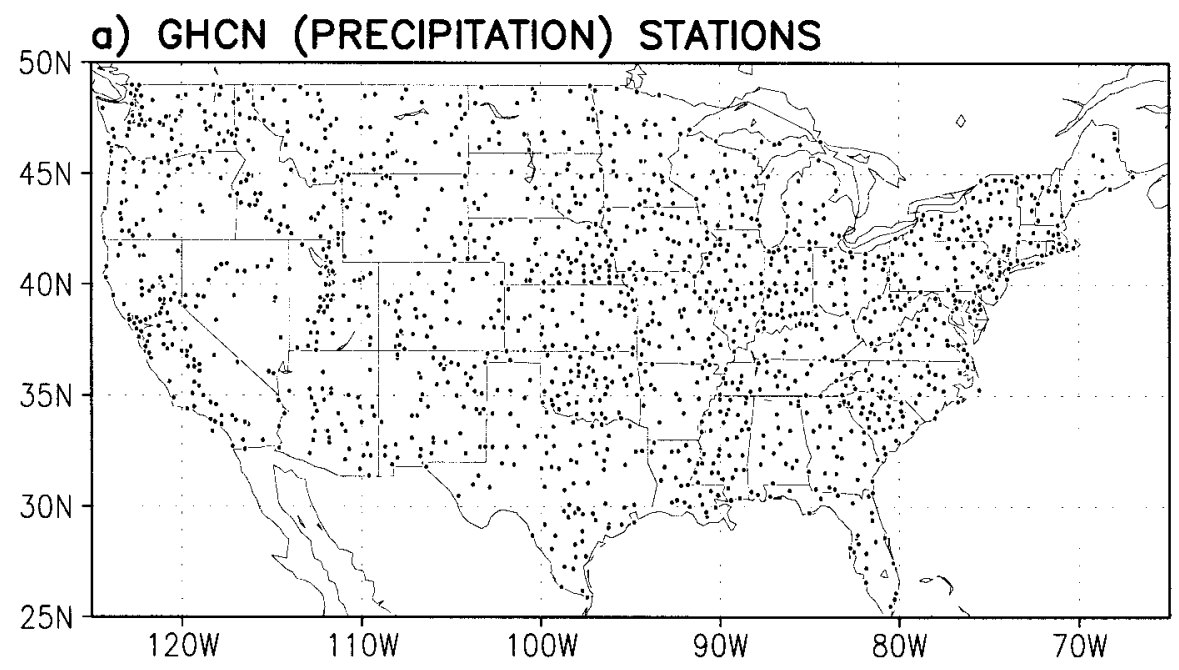

b) PDSI (DROUGHT) CLIMATE DIVISION CENTERS

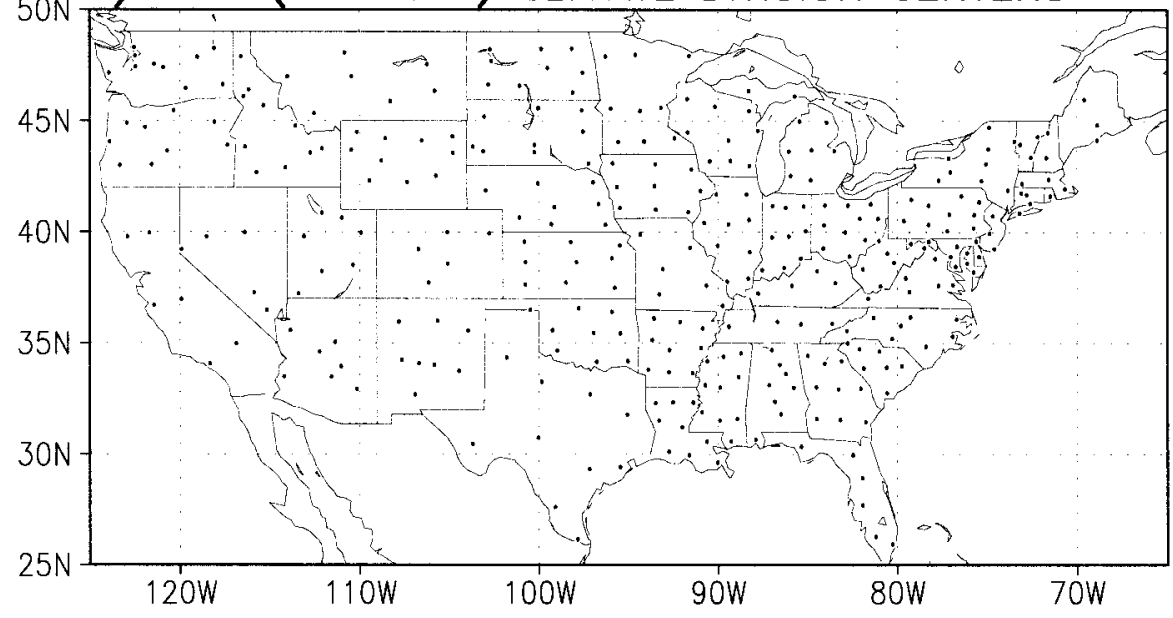

c) HCDN (RIVERFLOW) STATIONS

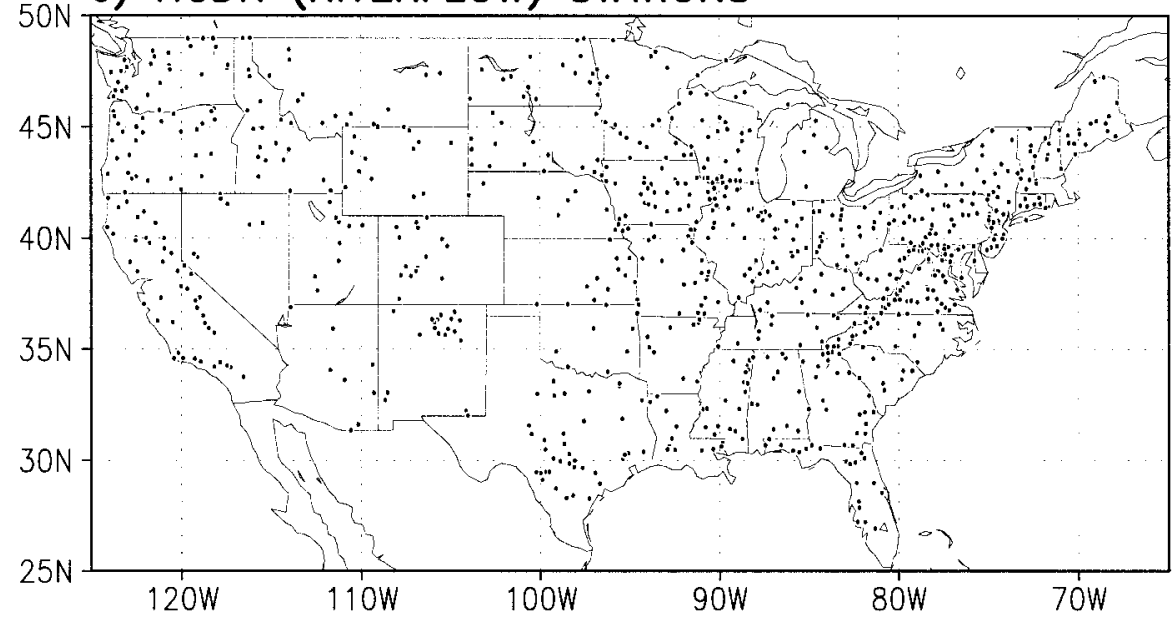

FIG. 1. (a) The station locations for the precipitation data. (b) The centers of the climate divisions for the drought index data. (c) The station locations for the stream flow data. 
statistical analyses were preformed on the raw station data with only the final results gridded onto a $2.5^{\circ}$ lat $\times 2.5^{\circ}$ long grid [using a Cressman-type analysis (Cressman 1959), with radii of 10, 7, 4, 2, and 1 in grid units]. We have recalculated the gridding at differing resolutions and with different Cressman radii of influence to verify that the $2.5^{\circ}$ lat $\times 2.5^{\circ}$ long grid accurately represents the station data, modestly smoothed. Finally, all calculations are shown with statistically significant stations (at the 95\% confidence level) denoted with a dot, to further allow assessment of the robustness of particular analysis features.

\section{d. Palmer drought severity index}

The PDSI is a monthly value indicating the severity of a wet or dry spell, based on a balance between the supply and demand of moisture calculated from a complex empirical relationship involving precipitation and temperature [see Palmer (1965) for the details of the calculation and Alley (1984) for a detailed critique]. Although often used as a measure of meteorological drought, the calculation involves parameterized evapotranspiration and soil moisture conditions, so it is also a measure of hydrologic drought (Alley 1984). Negative values represent dry spells and positive values represent wet spells, with values of 0.5 to -0.5 representing normal conditions. Values of -0.5 to -1.0 correspond to incipient drought, -1.0 to -2.0 to mild drought, -2.0 to -3.0 to moderate drought, and -3.0 to -4.0 to severe drought; values greater than -4.0 represent extreme drought. The same ranges, with opposite signs, hold for the strength of wet spells. The PDSI values are available for the 344 U.S. climate divisions (see Fig. 1b for the center positions of the divisions) for 1895-present; the data for 1945-93 were extracted. The calculation of the index attempts to account for different local climates and the seasonal changes, so that the values may be directly compared between different regions and different seasons. All computations were performed on the original divisional data and then gridded onto the same $2.5^{\circ}$ lat $\times 2.5^{\circ}$ long grid as precipitation.

\section{e. Stream flow}

Monthly mean values of stream flow for 1950-85 were extracted from the U.S. Geological Survey's Hydro-Climatic Data Network (HCDN) for the 987 stations reporting at least $75 \%$ of the time for each month, JuneAugust (see Fig. 1c for station locations). The HCDN dataset was developed to minimize the impacts of human influence by excluding measurements of humanregulated river flows and by careful quality control (Slack and Landwehr 1992). All computations were performed on the original station data with only the final results gridded onto the same $2.5^{\circ}$ lat $\times 2.5^{\circ}$ long grid as the other variables. While stream flow stations represent specific geographic locations and processes, rath- er than samples of a continuous field, the station data nevertheless show a considerable amount of spatial coherence. We have verified that the gridding, while perhaps counterintuitive, does indeed provide an accurate, modestly smoothed version of the individual station data. The regional coherence of U.S. stream flow, as well as its independence from natural drainage divides, has been documented by Lins (1997), and contour plots of stream flow are not uncommon (see, e.g., Cayan and Webb 1992; Lins 1997).

\section{f. NCEP-NCAR reanalyses}

The NCEP-NCAR monthly reanalysis fields (Kalnay et al. 1996) for the 1958-93 period, at $2.5^{\circ}$ lat $\times 5^{\circ}$ long resolution, were used to provide an estimate of winds, streamfunction, and divergence. The NCEPNCAR reanalysis uses a spectral statistical interpolation scheme in conjunction with a T62 $(\sim 210 \mathrm{~km})$ spectral model with 28 vertical sigma levels. The wind and streamfunction data are considered to be " $\mathrm{A}$ " class variables, the most reliable class, indicating a strong influence by the observational data. Horizontal divergence was calculated from the wind components and, as a derived quantity, is less reliable.

\section{Primary modes of Pacific SST variability}

\section{a. Methodology}

A covariance-based RPCA is used to extract the primary modes of SST variability from monthly data, $1945-93$, for the Pacific basin north of $20^{\circ} \mathrm{S}$, with nine modes rotated under the "VARIMAX" criterion (see, e.g., the discussion in Richman 1986). The monthly annual cycle has been removed from the data. With RPCA, the number of rotated modes should be large enough that all relevant information is included but small enough so that irrelevant information ("noise") is not included. This was assessed by determining the range of number of rotated modes where the structures of the first three modes (and their regressions to the hydrologic variability) were stable; the rotation of nine modes is representative of this stable range. VARIMAX rotation maintains the constraint (from the unrotated calculation) that all modes be temporally uncorrelated. In order to verify that this constraint is not significantly impacting the analysis, we have redone the analysis with each of the first three modes removed in turn (using the spatial patterns and time series of the original analysis). ${ }^{2}$

\footnotetext{
2 That is, three additional analyses were performed: one with ENSO removed, one with the PDO removed, and one with the North Pacific mode removed. In each, the mode was removed from the original SST data by subtracting out, for every month, the spatial pattern of the mode multiplied by the time series value for that month. RPCA was then performed on the resulting data. Since the analysis requires all modes to be uncorrelated to each other, removing a mode frees
} 
For each of the first three modes, removal of one mode does not materially effect the other two, with the ordering and characteristic spatial and temporal characteristics of the modes essentially unchanged. Although the analysis of hydroclimate linkages focuses on summer, all calendar months are used in the SST analysis. Inclusion of all months of the year is the most appropriate sampling for monthly data (Madden 1999) and includes the most information (we have verified that all three modes of interest are active throughout the year). Similar SST modes and associated hydroclimate regressions result from a summer-only analysis. As noted in the previous section, the calculation is done on an equal-area grid to prevent bias toward the northerly latitudes, which are overrepresented in a latitude-longitude grid. A comparison with the same modes extracted from the longer-term (1900-91) data, the rationale for this technique, and a comparison with unrotated and regional analysis are presented in section 6 .

\section{b. Extracted modes}

The spatial patterns for the first three modes are displayed in Fig. 2, with the associated time series shown in Fig. 3. The ordering is based on explained variance for the full domain. The spatial patterns of the modes (Figs. 2a-c) are derived from all calendar months; given the U.S. warm season focus in this analysis, the JuneAugust contribution to the modes are also shown (Figs. 2d-f). The first mode (Figs. 2a and 3a) is typical of modal extraction of ENSO (e.g., Weare et al. 1976), with a spatial pattern similar to well-developed ENSO conditions (e.g., Rasmusson and Carpenter 1982; Nigam and Shen 1993). The spatial pattern of the mode (Fig. 2a) includes all calendar months and essentially represents an average over the ENSO evolution. Since the ENSO evolution is phase-locked to the annual cycle (Rasmusson and Carpenter 1982), the summer contribution (Fig. 2d) more closely corresponds to a specific time in the evolution: the initial development of large central Pacific anomalies. Even though time filtering has not been used, the results for ENSO are quite similar to the 6-yr highpass analysis of Zhang et al. (1997; cf. their Fig. 3), confirming that spatial pattern is sufficient to separate ENSO from the lower-frequency variability.

The second mode (Figs. 2b and $3 b$ ) is referred to in this study as the Pacific decadal oscillation (PDO), due to the full-basin extent of the spatial pattern and the long timescales present in its evolution and in correspondence to previous studies. This rotated realization of the PDO is broadly similar to that of Mantua et al. (1997), and the "ENSO-like decadal" mode of Zhang

the other modes from being forced to be uncorrelated to it. Removing each of the modes, in turn, allows an assessment of whether the restriction of being mutually uncorrelated is affecting the structure of the modes. et al. (1997), but with less signal in the North Pacific and in the equatorial eastern Pacific. As in both of those studies, the evolution of this mode captures the striking SST changes centered on 1976-77 (e.g., Trenberth 1990). ${ }^{3}$ Although the PDO has some similarities to ENSO in the North Pacific, the differences in tropical structure are quite large. The summertime structures highlight this difference in the equatorial eastern Pacific during summer (cf. Figs. 2d,e). The structural differences between the PDO in this analysis and in previous studies are due to the rotation of modes here [a more physically motivated choice; see Richman (1986)], and to the larger domain of the current study, which, for the PDO, introduces more relevant information. These effects are considered explicitly in the sensitivity analysis in section 6.

The third mode (Figs. 2c and 3c) is referred to here as the North Pacific mode, due to its restriction to that region. The associated time evolution reflects both decadal-scale fluctuations and strong interseasonal variations. Variants of this mode have also been previously extracted, as discussed in the introduction, and its spatial relationship with the North Pacific Ocean's arctic frontal zone has been noted (Nakamura et al. 1997). Note that, although most previous analyses of this mode have concentrated on the wintertime structure, the mode is quite vigorous in summer (Fig. 2f). The summertime vigor and all-season persistence of the North Pacific variability have also been discussed by Zhang et al. (1998) and Norris et al. (1998); Norris et al. have noted the close association between local marine stratiform cloudiness and the SST anomalies.

The time series for each of the three modes is very similar to the SST data at the grid box closest to the maximum spatial loading. Indeed, the spatial patterns of the modes are easily found in the unprocessed SST data by regressing to $\mathrm{SSTs}$ at $\left(110^{\circ} \mathrm{W}, 0^{\circ}\right),\left(20^{\circ} \mathrm{N}\right.$, $\left.125^{\circ} \mathrm{W}\right)$, and $\left(40^{\circ} \mathrm{N}, 160^{\circ} \mathrm{W}\right)$, respectively. It is important to note, therefore, that the spatial distinction between the three modes is a product of the SST data, itself, not the RPC technique.

Since both the PDO and the North Pacific mode have substantial high-frequency variability, highly smoothed ${ }^{4}$

\footnotetext{
${ }^{3}$ A cautionary note: the current analysis reveals that examination of the transition in $1976 / 77$ based on simple averages can be misleading, due to the simultaneous activity in the Pacific of two lowfrequency modes. The North Pacific mode, which does not transition in 1976/77, is, however, mostly positive before 1972 and mostly negative afterward, in the 1945-93 period. Therefore, calculation of the transition based on pre- and post-1976/77 data in the 1945-93 period will inadvertently include some features of the North Pacific mode.

${ }^{4}$ The smoothing was calculated by 96 iterations of a 1-2-1 time filter on the original time series. Each iteration of the 1-2-1 filter replaced every monthly value with an average of twice the value and the two neighboring values; at the end points the values were replaced by an average of twice the value and the single neighboring value.
} 
ANNUAL PATTERN
JUNE, JULY, AUGUST

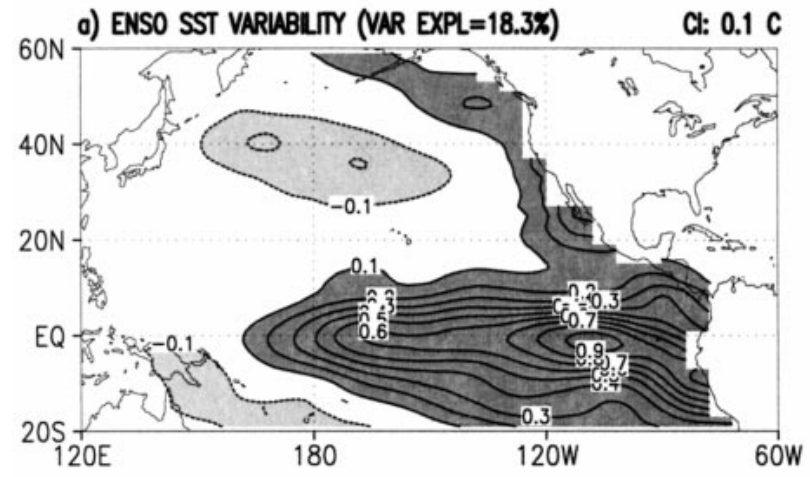

b) PACIFIC DECADAL SST VARIABILTYY (VAR EXPL=7.5\%) Cl: 0.1 C

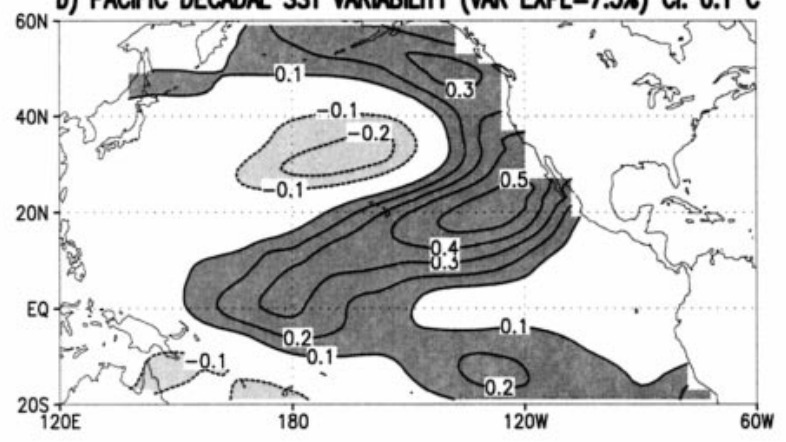

c) NORTH PACIFIC SST VARIABILTY (VAR EXPL=5.1\%) Cl: $0.1 \mathrm{C}$

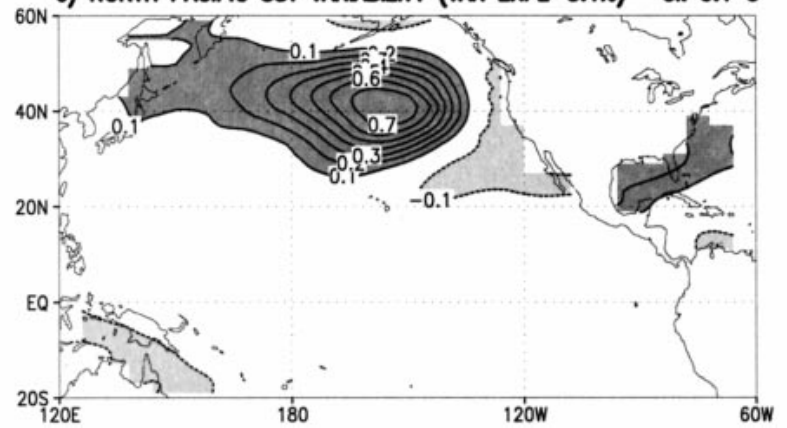

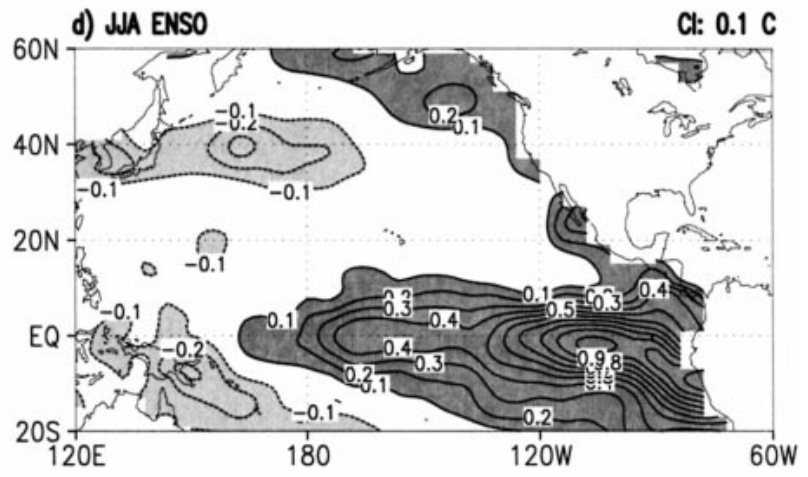

e) JAA PACIFIC DECADAL Cl: $0.1 \mathrm{C}$
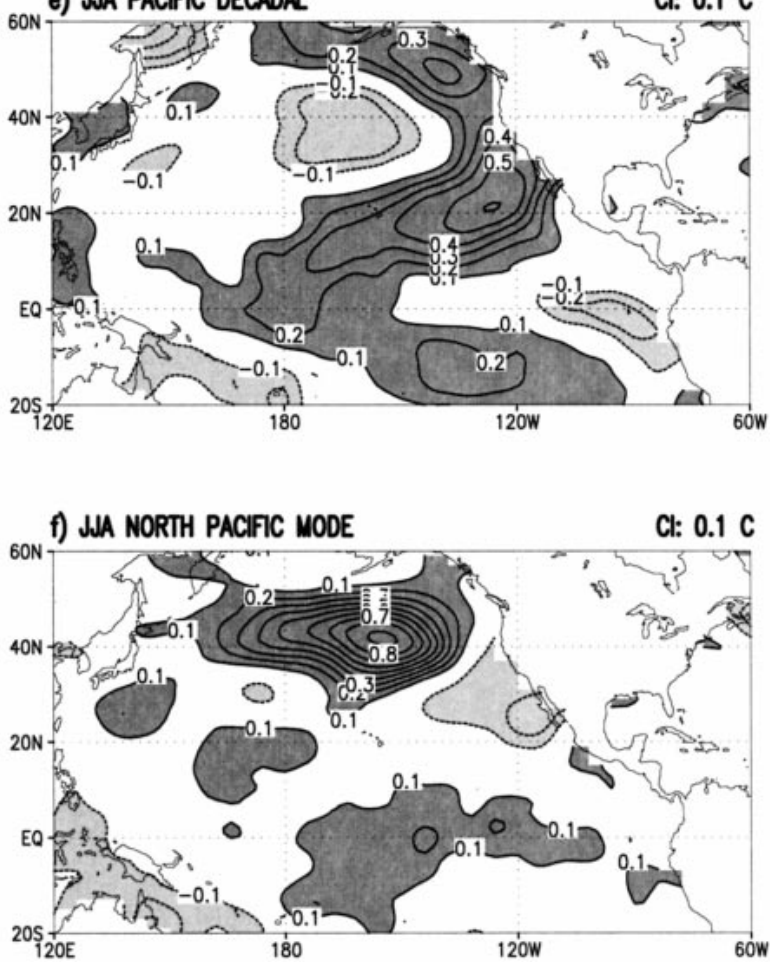

FIG. 2. The spatial patterns for the three leading modes of Pacific SST variability during 1945-93 obtained from rotated principal component analysis: (a) ENSO, (b) Pacific decadal, and (c) North Pacific. The corresponding patterns for only the Jun-Aug contributions to the modes are shown in (d)-(f). The domain shown is the analysis domain.

versions of the time evolutions (overlaid lines in Fig. 3 ) were used to verify that the spatial patterns were representative of the lower frequencies. "Decadal" is used here to refer to the timescales that are intermediate between interannual and secular. This rather broad definition is based on the observed variability of the modes as extracted here and on correspondence of terminology with previous analyses. Given the possibility of stochastic dynamics such as those suggested by Hassel- mann and Frankignoul (Hasselmann 1976; Frankignoul and Hasselmann 1977), a more narrow definition may be nonphysical.

As implied by the more limited analysis of Nakamura et al. (1997), there are two robust modes of Pacific decadal variability with signals in the North Pacific, so any discussion of the decadal signal in the Pacific or associated teleconnections must distinguish between the two modes. 


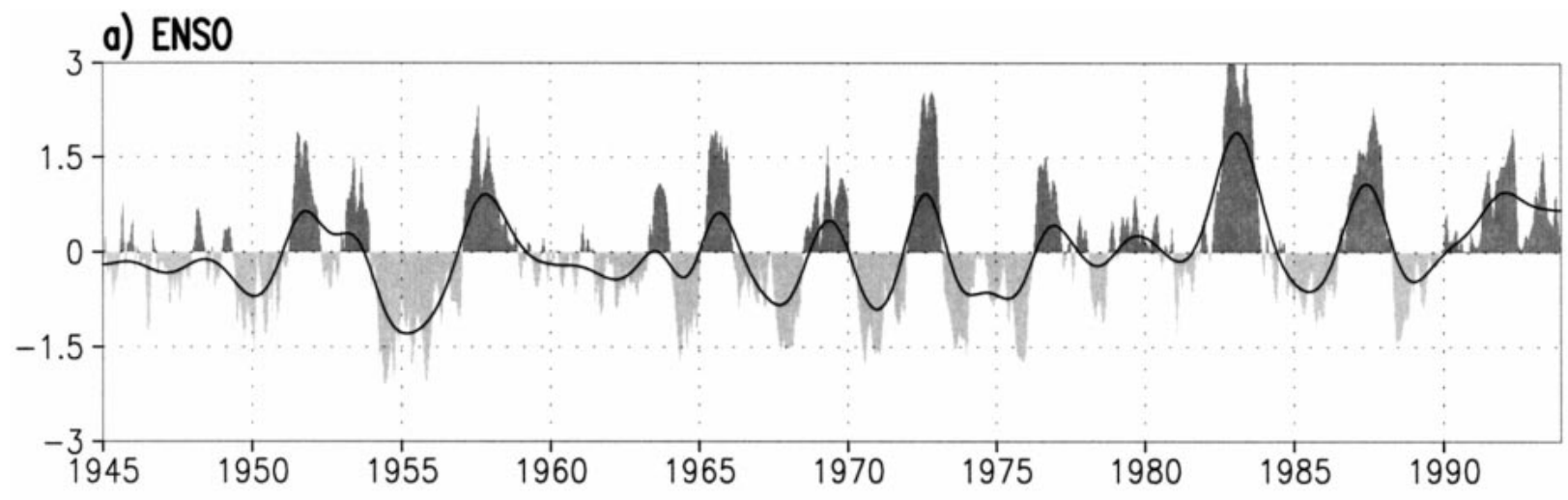

3 b) PACIFIC DECADAL OSCILLATION
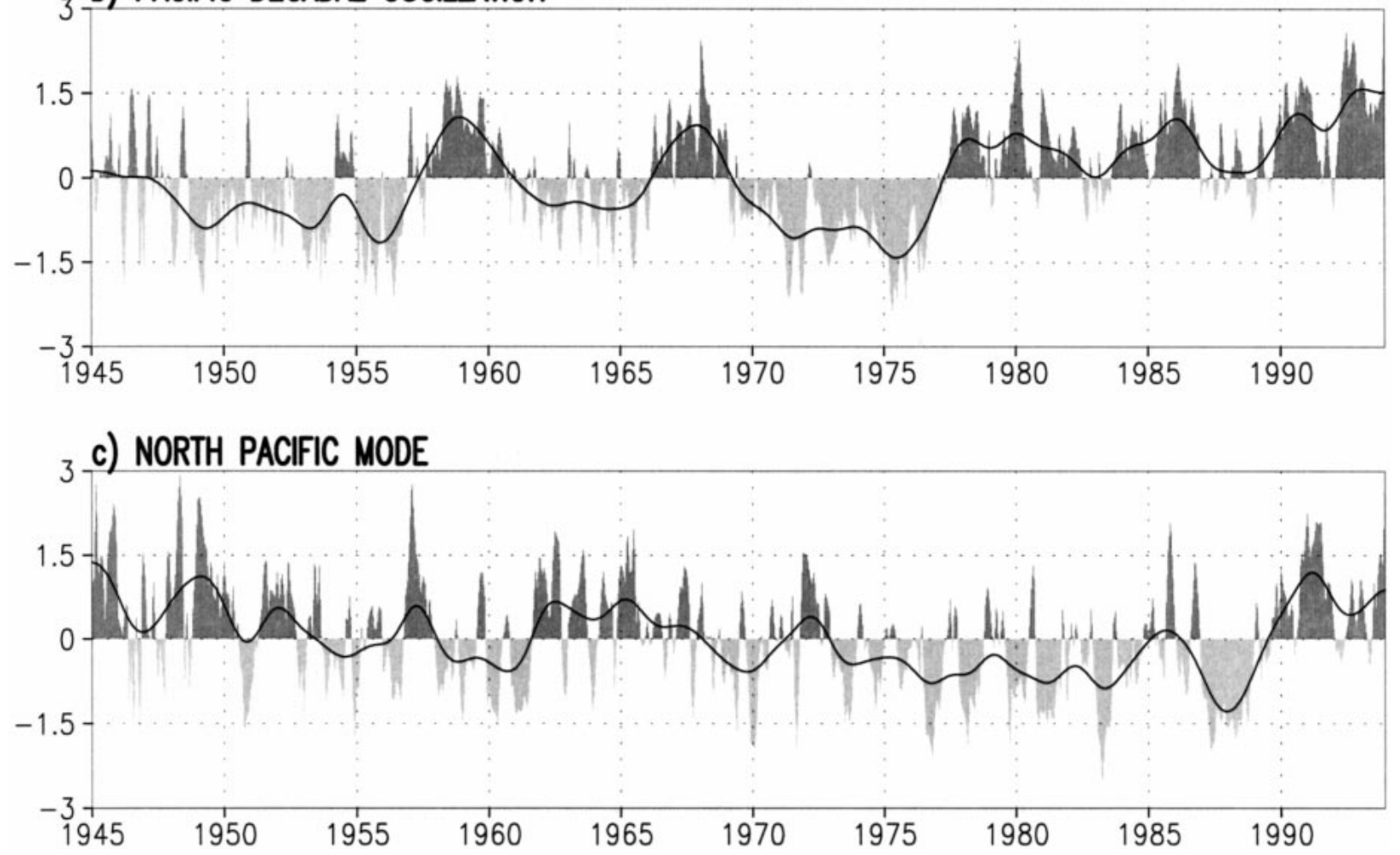

FIG. 3. The shaded curves are the principal components (time series) for the three SST modes: (a) ENSO, (b) Pacific decadal, and (c) North Pacific. The superimposed lines represent heavily smoothed versions of the time series.

\section{SST linkages to U.S. hydroclimate}

a. Warm season drought and stream flow relationships

The warm season (June-August) mean covariances between the three SST modes and U.S. PDSI and stream flow are shown in Fig. 4. Since the rotated principal components (time series) are all uncorrelated with each other (see section 3a), the relationships shown are linearly independent of one another.

ENSO is related to wet conditions in the west and central regions, in agreement with previous precipitation analyses (Ting and Wang 1997; Higgins et al. 1999).
The sign of the relationships as shown corresponds to the warm phases of the modes (e.g., El Niño), as seen in Fig. 2; the sign would reverse for the cold phases (e.g., La Niña).

The PDO is related to wet conditions extending from the southwest to the central regions, with strong negative values in the northern extent of the central and western regions. The North Pacific mode is primarily related to negative values extending diagonally from Texas through the Northeast. Both decadal modes have relationships comparable in strength to that of ENSO.

The drought index is an integrative variable, with current conditions strongly impacted by previous con- 


\section{JJA DROUGHT REGRESSIONS}

a) ENSO

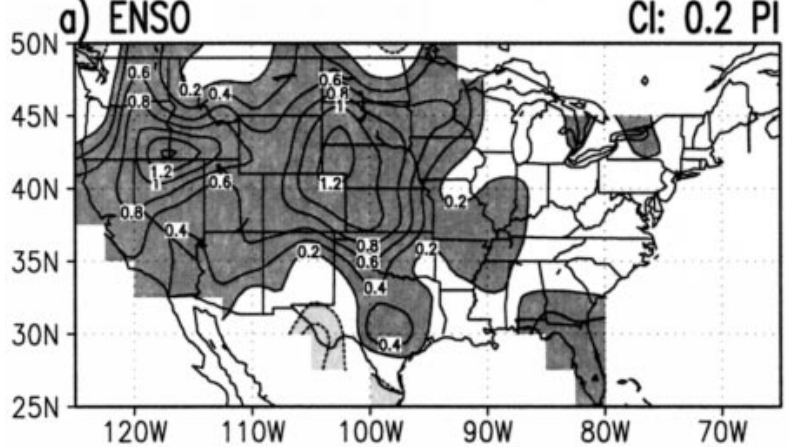

b) PACIFIC DECADAL

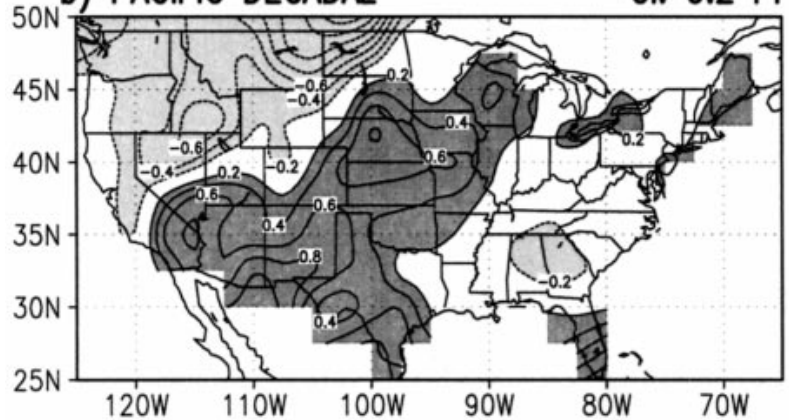

c) NORTH PACIFIC

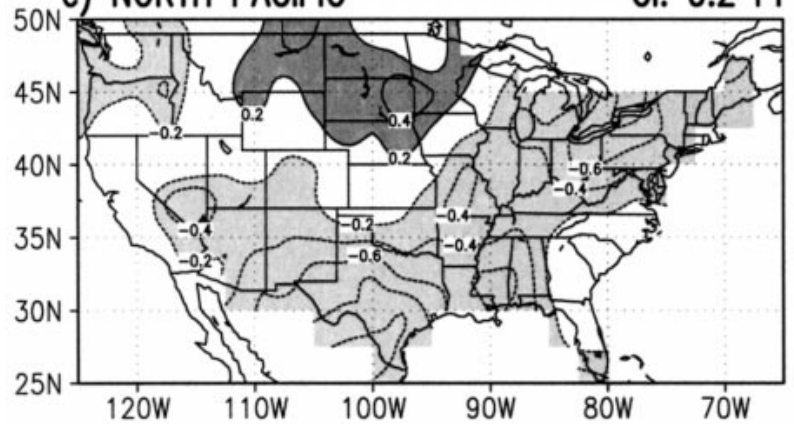

JJA RIVERFLOW REGRESSIONS
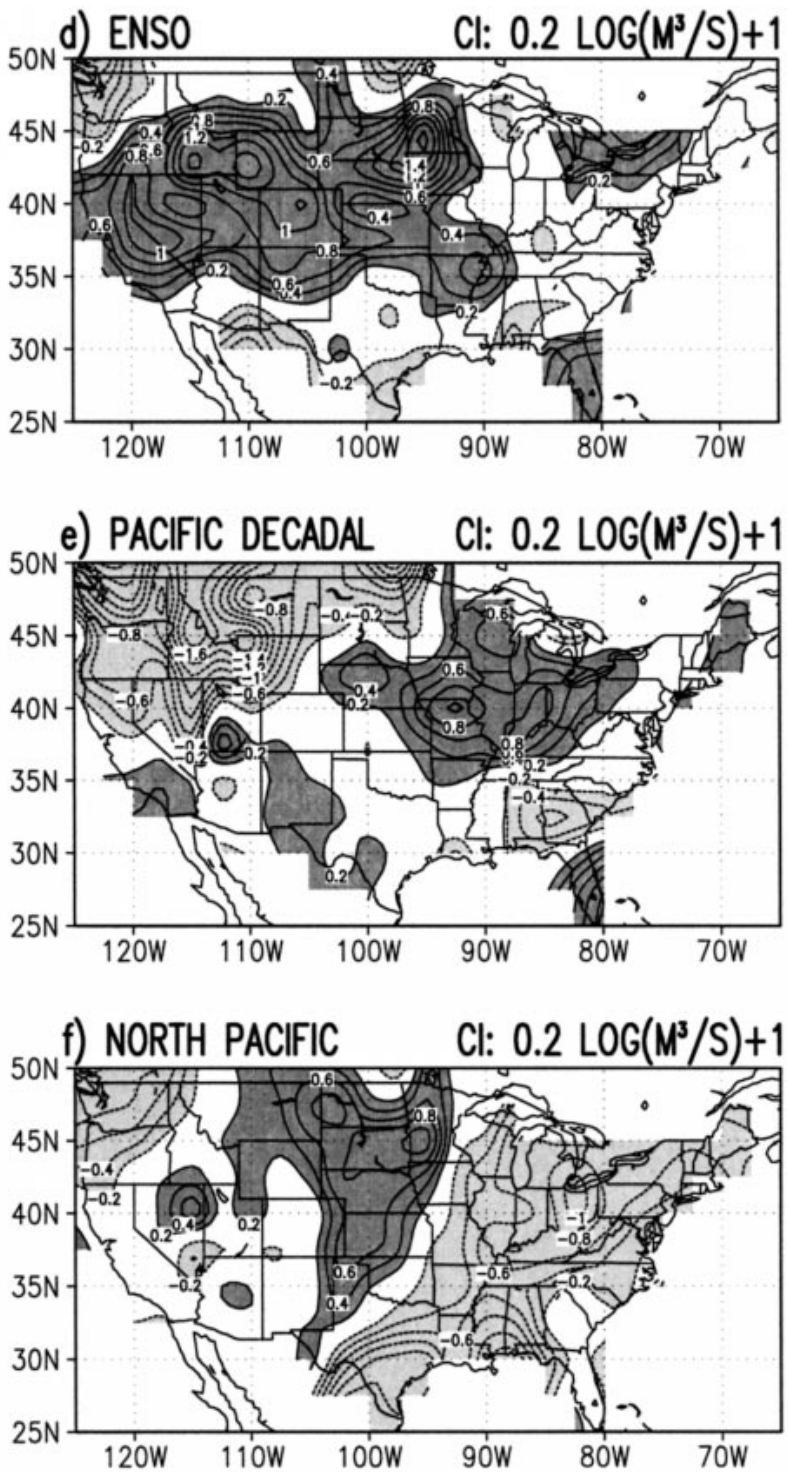

FIG. 4. The drought $[(a)-(b)]$ and stream flow [(c)-(d)] regressions with the SST principal components of the PDO and North Pacific modes averaged for Jun, Jul, and Aug. The drought regressions are in units of PDSI, while stream flow regressions are in the natural logarithm of stream flow, as $\log \left(\mathrm{m}^{3} \mathrm{~s}^{-1}\right)$. The PDSI indicates the severity of a wet (positive values) or dry (negative values) spell, based on a balance between the supply and demand of moisture calculated from a complex relationship involving precipitation and temperature. All computations were performed on the climate division data for Palmer index and on the station data for stream flow, 1950-88, and then gridded onto a $2.5^{\circ}$ lat $\times 2.5^{\circ}$ long spatial grid. Plots for both variables were made for the period of stream flow data availability (1950-88); drought data were available for $1945-93$, and results are very similar.

ditions (explicit in its empiric formula), so it varies slowly over the course of a season, so that the seasonal averages shown are quite representative of the monthly fields. Stream flow is also affected strongly by previous conditions and storage terms, such as snowmelt. It varies more within the season, but its quasi stationarity is shown by the good correspondence with drought index in the seasonal means. As has been previously noted for the general case (Lins 1997), the stream flow anomalies here do not closely correspond to natural basin areas. For both the PDSI and stream flow, RPCA of the variable itself yields patterns that are much more regionalized than the relationships shown here (Karl and Koscielny 1982; Lins 1997), a result consistent with external forcing for the large-scale relationships obtained in this analysis. 
a)-c) ENSO AND PRECIP

a) JUNE $\quad \mathrm{Cl}: 0.1 \mathrm{MM} / \mathrm{DY}$

b) JULY

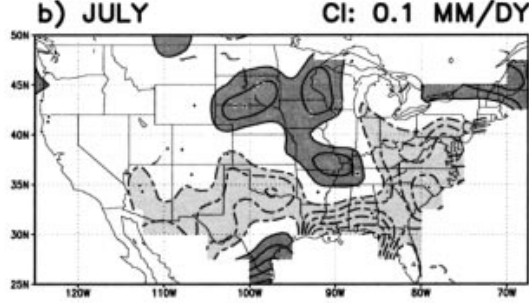

c) AUGUST

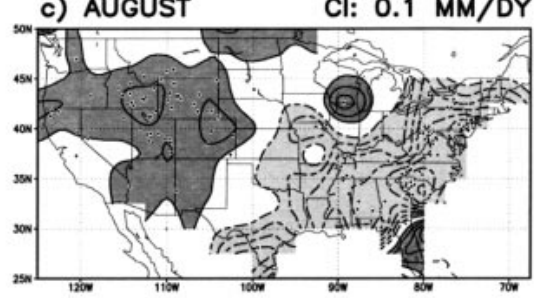

d) -f) PDO AND PRECIP d) JUNE

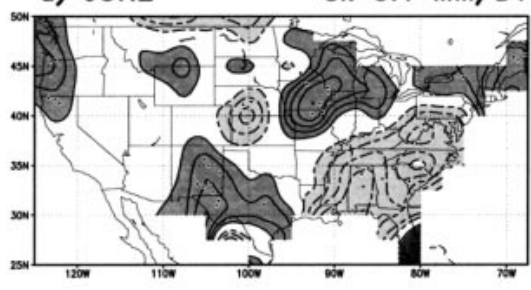

e) JULY

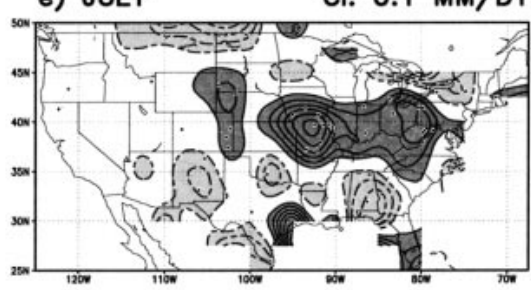

Cl: $0.1 \mathrm{MM} / \mathrm{DY}$

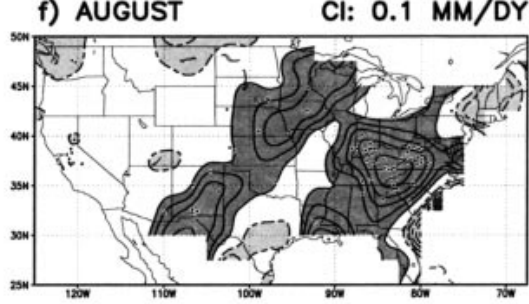

g)-i) NP MODE AND PRECIP

g) JUNE

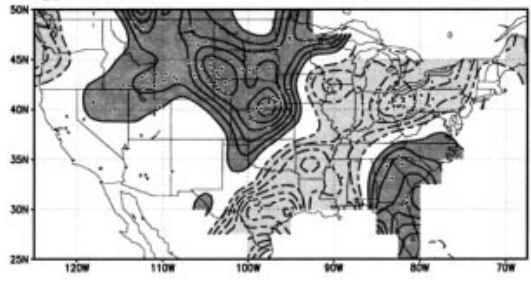

h) JULY

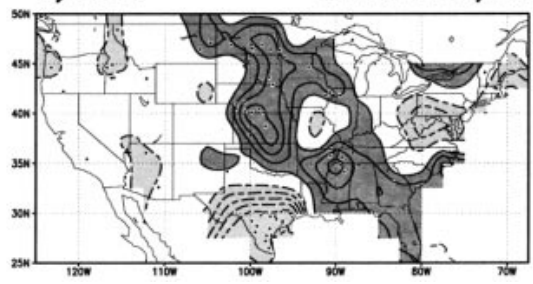

i) AUGUST

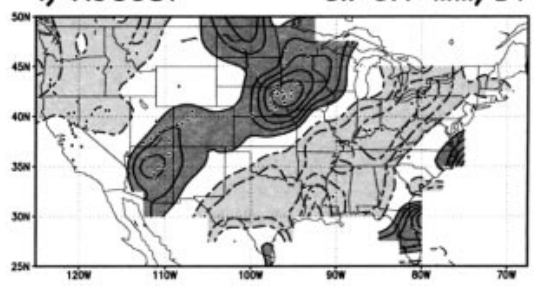

FIG. 5. The monthly precipitation relationships for the three SST modes: (a)-(c) ENSO, (a)-(f) PDO, and (g)-(i) North Pacific mode. Stations locally significant at the $95 \%$ level are denoted with a dot.

In general there is close agreement between the patterns in drought index and stream flow, except for regions in the Southwest, following an arc through Arizona, New Mexico, and the western extent of Texas, Oklahoma, and Kansas (e.g., compare the differences between Figs. 4c and 4f). This is a region of low mean stream flow in the summer, so the memory of stream flow is greatly reduced. This decreased memory, in turn, reduces stream flow's local agreement with the high memory drought index.

The relationships were also computed with heavily smoothed versions of the time series (see Fig. 3) to verify that the relationships were associated with the lower-frequency variability of the modes. The statistical field significance (as in Livezey and Chen 1983; Wilks 1995) was calculated for each relationship from the raw climate division and station data, and is $97 \%, 92 \%$, and $96 \%$, respectively, for the three drought relationships and $92 \%, 96 \%$, and $99 \%$ for stream flow. This significance calculation accounts for abnormal distribution, spatial correlation, spatial multiplicity, and-very important for these cases-the temporal autocorrelations associated with the low frequencies of both the SST time series and the drought and stream flow data.

\section{b. Monthly precipitation relationships}

Given the importance in the timing of precipitation anomalies, to agriculture, for example, it is important to assess not only the seasonal hydrologic signals but also the monthly relationships. Monthly calculations for the drought and stream flow (not shown) verify that the relationships vary only slowly over the course of the season (with stream flow varying slightly more than drought). The monthly precipitation relationships, however, change markedly. The relationships between precipitation and the three SST modes computed for June, July, and August, separately, are shown in Fig. 5. While a seasonal average of the precipitation relationships looks similar to the corresponding drought and stream flow relationships shown in Fig. 4 in the eastern threequarters of the United States (there is little summer precipitation in the western quarter), there are very strong 
intraseasonal variations that are not reflected in a seasonal average.

We have verified the stability of the monthly analysis by both recalculating the analysis with only a randomly chosen third of the months and examining the monthly evolution for the warm phase and cold phase, separately. Features associated with a cluster of three or more locally significant stations (denoted by dots in the figure) are generally robust. Further, monthly evolution generated from only the lower-frequency variability of the modes (the smoothed time series in Fig. 3) is quite similar to what is shown.

For ENSO, there is a striking evolution along the East Coast, which is very wet in June, somewhat dry in July, and then very dry in August, in agreement with the monthly Southern Oscillation index analysis of Richman et al. (1991). For the PDO, the position and pattern of the positive values in the central United States varies notably over the course of the season. For the North Pacific mode, both June and August look quite similar to the seasonal mean (cf. Fig. 4f), but the intervening month, July, does not. At the monthly timescale, areas that appear to be only weakly affected in the seasonal mean (e.g., the East Coast for the ENSO case), can actually have a large precipitation signal. This intraseasonal evolution is understandable in light of the notable evolution of the climatological circulation over North America during the warm season [e.g., the onset of the Mexican monsoon (Barlow et al. 1998)]. Modeling of the North Pacific-North American response to remote low-frequency forcing has been shown to be sensitive to the annual cycle at the monthly timescale (Newman and Sardeshmukh 1998).

As previously noted, the western extent of the drought and stream flow signals does not appear to be forced by the June-August precipitation, consistent with the small amount of local summer precipitation. Hydrologic memory is to be expected in this largely mountainous region, with a considerable snowpack. Understanding the full summer hydrologic signal will require consideration of previous seasons, with a careful analysis of storage terms.

\section{c. Warm phase-cold phase comparison}

The asymmetry of ENSO's atmospheric teleconnections between warm phase (El Niño) and cold phase (La Niña) is well known (e.g., Halpert and Ropelewski 1992; Hoerling et al. 1997). In particular, the response of U.S. precipitation to tropical SSTs has also been shown to be sensitive to the sign of the SST anomaly (Montroy et al. 1998). Further, a modeling analysis of wintertime response to North Pacific SST anomalies was shown to be asymmetric, as well (Kushnir and Lau 1992). It is of considerable interest, then, to consider the differences in U.S. hydrologic relationships for positive anomalies (warm phase) and negative anomalies (cold phase) associated with the modes. This is shown in Fig. 6. ENSO, unsurprisingly, has a stronger signal associated with the warm phase, and the central U.S. maximum is slightly more to the north. The PDO is largely symmetric, with somewhat more strength in the central United States during its cold phase. The North Pacific mode retains the band of negative values from Texas to the Northeast in the cold phase, but more weakly. The negative drought index values extend to the north in the western region somewhat more in the cold phase. The warm phase-cold phase stratification of the modes, themselves (i.e., in SST), is much more symmetric.

Although the strength of the relationships varies considerably from warm phase to cold phase, the overall patterns remain similar, maintaining the same centers of action. In addition to quantifying the warm phase-cold phase differences, this separation also demonstrates that the patterns are not the result of a particular period or single extreme event.

\section{d. Atmospheric teleconnections and stationary wave activity}

The Plumb flux, an extension of the Eliassen-Palm relation, is a useful diagnostic for identifying possible source regions for stationary waves (Plumb 1985). The horizontal Plumb flux, $F$, is given as

$$
\begin{gathered}
F=\left\{\frac{p}{2 a^{2} \cos \phi}\left[\left(\frac{\partial \psi^{\prime}}{\partial \lambda}\right)^{2}-\psi^{\prime} \frac{\partial^{2} \psi^{\prime}}{\partial \lambda^{2}}\right],\right. \\
\left.\frac{p}{2 a^{2}}\left(\frac{\partial \psi^{\prime}}{\partial \lambda} \frac{\partial \psi^{\prime}}{\partial \phi}-\psi^{\prime} \frac{\partial^{2} \psi^{\prime}}{\partial \lambda \partial \phi}\right)\right\},
\end{gathered}
$$

where $p$ is the pressure level, $a$ is the radius of the earth, $\phi$ and $\lambda$ are latitude and longitude, $\varphi$ is streamfunction, and a prime denotes deviation from the zonal mean (the "eddy" component). As shown by Karoly et al. (1989), the Plumb flux diagnostic of stationary wave activity clearly captures the Tropics-to-extratropics Rossby wave propagation from a tropical heating source, as realized in a linear model. They note, however, that in the real atmosphere, tropical heating appears to affect the extratropics in a more complicated fashion, perhaps through modulation of the subtropical jet via a local Hadley-like circulation generated by the tropical heating. The tropical-extratropical connection, in this case, will not be reflected solely in stationary waves and so may not be fully revealed by Plumb flux analysis. For example, the stationary wave activity associated with (wintertime) ENSO is largely confined to the extratropics. The Plumb flux diagnostic, then, is useful for identifying the source region and propagation of stationary wave activity but not necessarily the original physical forcing region.

Figure 7 shows the $300-\mathrm{hPa}$ eddy streamfunction anomalies and the associated stationary wave activity for the three SST modes. Due to the shorter overlap 


\section{WARM PHASE IN DROUGHT}

a) ENSO
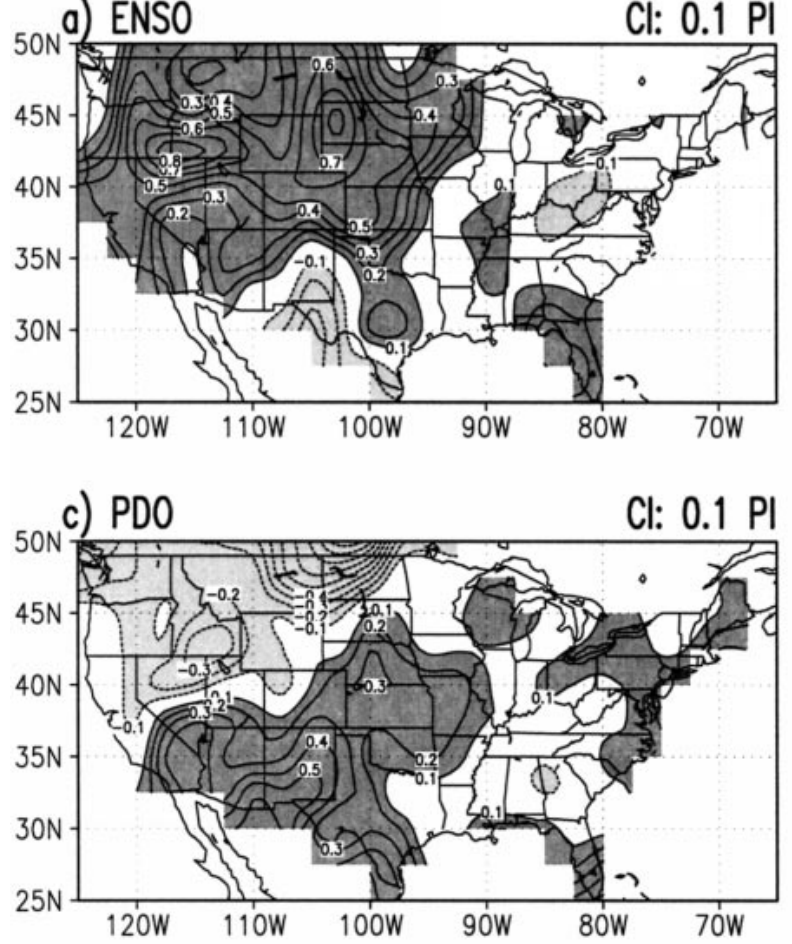

e) N PACIFIC MODE

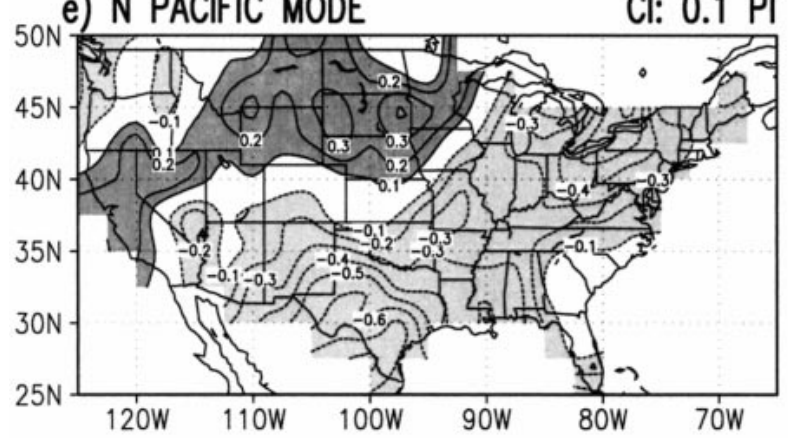

COLD PHASE IN DROUGHT (SIGN REVERSED)
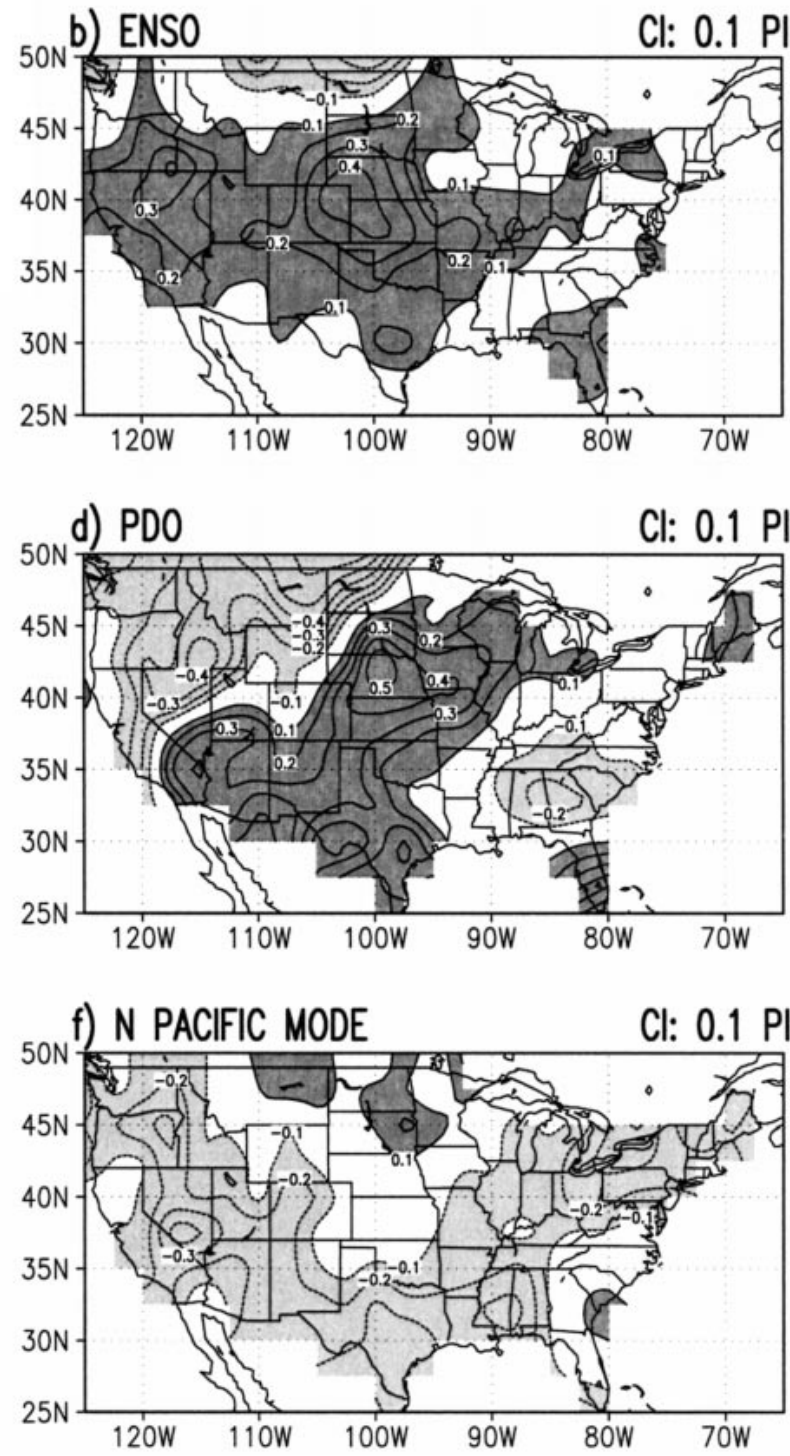

FIG. 6. Drought relationships calculated only for positive (warm phase) and negative (cold phase) values of the three principal components. Warm phase relationships: (a) ENSO, (c) PDO, and (f) North Pacific mode. Cold phase relationships: (b) ENSO, (d) PDO, and (f) North Pacific mode. The values are in terms of the contributions to the total covariances; the warm phase and cold phase relationships will sum exactly to the general covariances in Figs. 4a-e.

between the NCEP-NCAR reanalysis and the precipitation and stream flow data (the atmospheric data begin in 1958, the precipitation and stream flow data in 1950), statistical significance was not calculated, and the results should be considered suggestive, rather than conclusive.

The summertime relationship with ENSO (Fig. 7a) shows the expected upper-level anticyclone in the tropical central Pacific, as well as somewhat weak anomalies throughout the region. A flux of stationary wave activity is present from the eastern North Pacific across the United States. In terms of simplified Gill-Matsuno-type dy- namics (Gill 1980), a Kelvin wave packet is expected to the east of the central Pacific tropical heating associated with ENSO. The tropical branch of the upperlevel cyclonic circulation over the Caribbean is consistent with this and suggests that the southeastern United States may be influenced by both propagating anomalies from the west and more directly forced local anomalies.

The summertime anomalies associated with the PDO (Fig. 7b) are mostly north of $30^{\circ} \mathrm{N}$, despite the tropical SST signal of the mode. A coherent set of three centers of streamfunction anomaly, largely equivalent baro- 


\section{a) ENSO 300hPo STAT WAVE ACTIVITY}

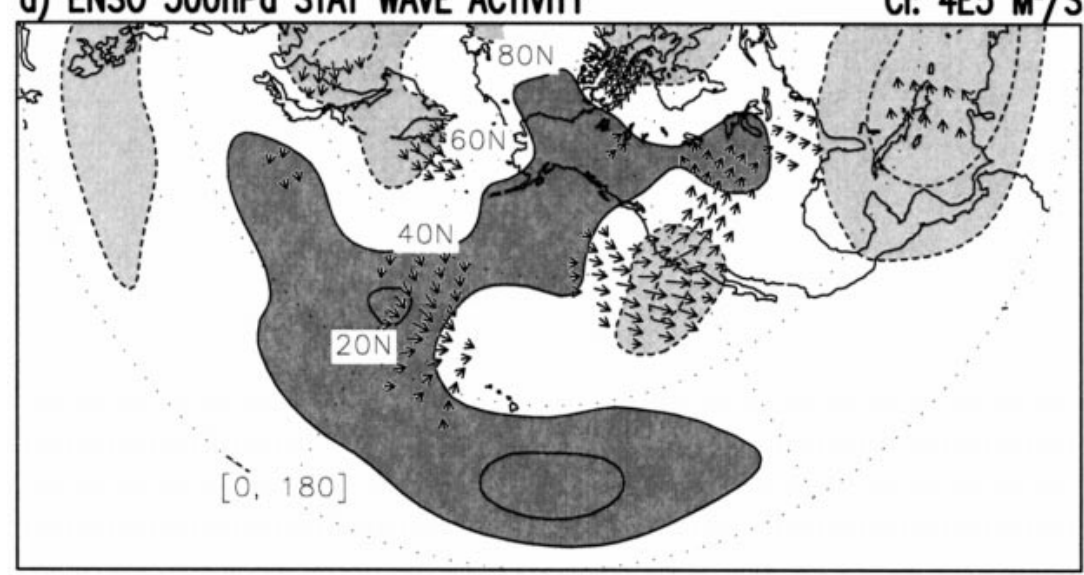

b) PDO 300hPo STAT WAVE ACTMITY

Cl: $4 \mathrm{E} 5 \mathrm{M}^{2} / \mathrm{S}$

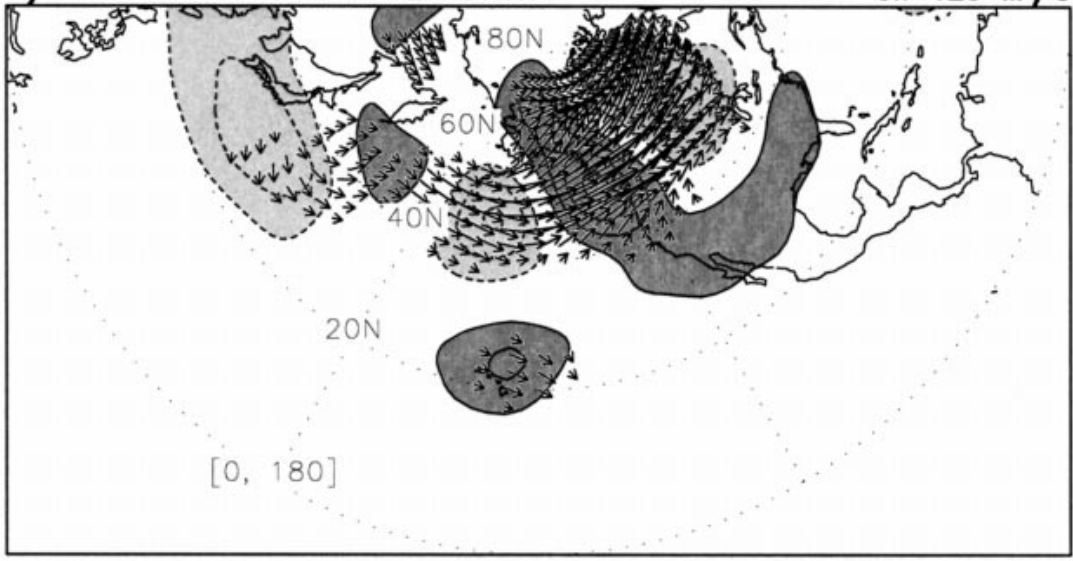

c) NP 300hPo STAT WAVE ACTIMTY

Cl: 4E5 M²/S

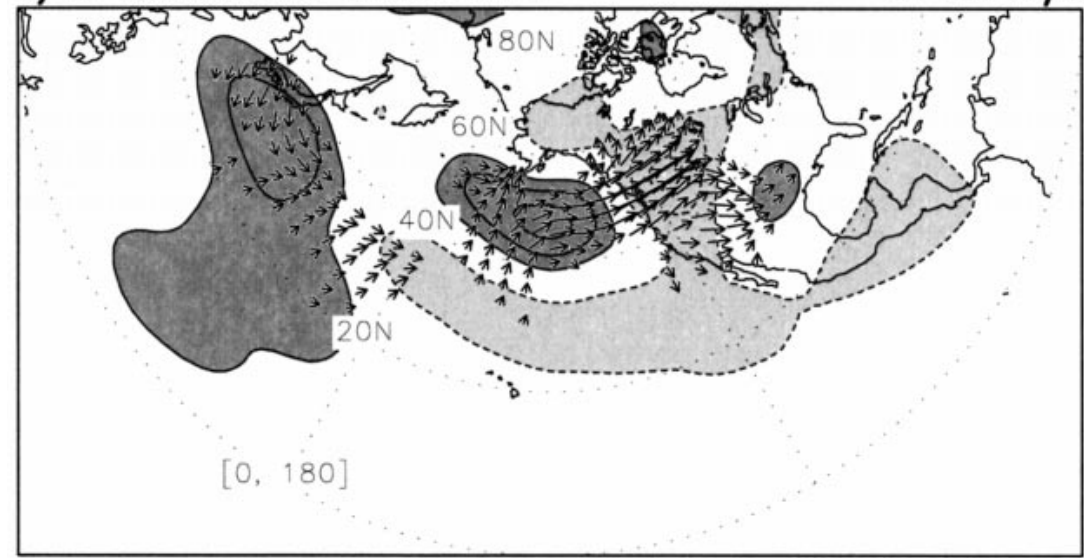

FIG. 7. Horizontal stationary wave activity flux vectors and streamfunction anomalies (zonal mean removed) for Jun-Aug, at $300 \mathrm{hPa}$, for (a) ENSO, (b) Pacific decadal, and (c) North Pacific. 
tropic in character (not shown), extend from the central North Pacific across the northern part of the United States. Associated with these is a large (compared to ENSO) flux of stationary wave activity. The ridging and troughing over the United States, through modulation of the jet and associated baroclinic activity, is consistent with wetter conditions in the central and eastern regions and drier conditions in the Northwest (see the drought pattern in Fig. 4b). Wet conditions in the Southwest are consistent with the local upper-level ridging enhancing the summertime monsoon-like precipitation of that area.

In the summertime anomalies associated with the North Pacific mode (Fig. 7c), a coherent doublet of anomalies exists, with a positive center over the eastern central Pacific and a negative center over the western United States. Associated with these anomalies is a flux of stationary wave activity, splitting to the north and south over the western United States. The southern branch extends more weakly, recurving back in the northeastern United States (not visible at displayed vector magnitudes). The weaker features are also nearly equivalent barotropic. The region of upper-level negative values over the Northeast corresponds to a surface cyclonic circulation. This circulation opposes the climatological influx of moisture into the eastern United States associated with the western extension of the Bermuda high. This appears to be consistent with the belt of negative anomalies in the hydrologic variables.

This presents a consistent, if somewhat broad, picture of the relationship between the three modes of Pacific SST variability and the U.S. hydrologic anomalies. All three SST modes are associated with stationary wave flux from the North Pacific, extending into the United States. The streamfunction (height) anomalies associated with this flux are roughly equivalent barotropic in structure, consistent with remote forcing. The largescale atmospheric anomalies over the United States are, in turn, generally relatable to the associated drought patterns. The dynamical mechanism linking the ocean surface temperature anomalies and the atmospheric circulation anomalies over North America, however, remains to be elucidated.

\section{Specific long-term droughts}

\section{a. 1952-56 central U.S. drought}

The drought of the 1950s was both large in scale and severe, and lasted from approximately 1952 to 1956 (e.g., Diaz 1983); the observed PDSI for the summers of this period is shown in Fig. 8a. While drought conditions existed over most of the United States, the most severe values extended north from Texas through Kansas. In the Pacific Ocean, both the PDO and ENSO were active during this period (see Fig. 3), mostly in their respective cold phases, and the observed SST anomalies (Fig. 8b) reflect a mix of the cold phases of the two modes. Since a general drought relationship has been calculated for each mode, the time series for each SST mode may be averaged for the period, multiplied by the corresponding drought relationship, and summed, to yield the drought signal linearly associated with the three SST modes. That is, the loading values (spatial patterns) for each mode have been multiplied by the respective time-averaged principal components (time series). This is shown in Fig. 8c, with half of the contour interval used to display the observed values. (The indices for the three modes during this period, averaged from the time series in Fig. 3, were $-0.61,-0.69,0.24$, respectively.) While the correspondence between this computed drought and the observed values is far from perfect, particularly in terms of magnitude, the computed drought does capture the maximum of drought extending north from Texas to the central United States. Given the strong local hydrologic feedbacks active in drought (e.g., Lyon and Dole 1995), as well as the possibility of somewhat longer-term feedback due to storage terms such as snowpack, it is possible that the $\mathrm{Pa}-$ cific SSTs may determine structural aspects of the drought, with the magnitude dependent on local feedbacks. Alternatively, it is possible that the influence of Pacific SSTs is modulated by some other large-scale factor and only fully develops under particular conditions. For example, SST anomalies also exist in the central North Atlantic during this period and it is possible they play an active role in the development of the drought.

\section{b. 1962-66 northeastern U.S. drought}

Another long-term severe drought episode occurred in the Northeast during the 1960s, from about 1962 to 1966 (Namias 1966, 1967); the observed summertime drought anomalies are shown in Fig. 9a. Note that the severe drought over the Northeast is accompanied by a large-scale pattern of drought index anomalies.

As noted by Namias, the SSTs during this period exhibited warm anomalies in the eastern North Pacific and an area of negative anomalies off the northeastern coast of the United States. Given the pattern of Pacific anomalies, the North Pacific mode would be expected to be active; it was, with an average index value of 1.0 (ENSO SST activity averages to almost zero during the period, and the PDO average index is -0.62). It is important to remember that principal component-type analysis is forced to extract a full set of modes and will do so even from random data. In addition to the stability analysis discussed in section $3 \mathrm{a}$, the coherent expression of the North Pacific mode in five years of observed data, as shown here, provides strong evidence that the mode is not a statistical artifact. The coherence of the warm phase of the mode in a 5-yr average also validates the consideration of the mode as decadal scale.

The linearly related SST drought signal can be computed as before, as shown in Fig. 9c. As expected from 

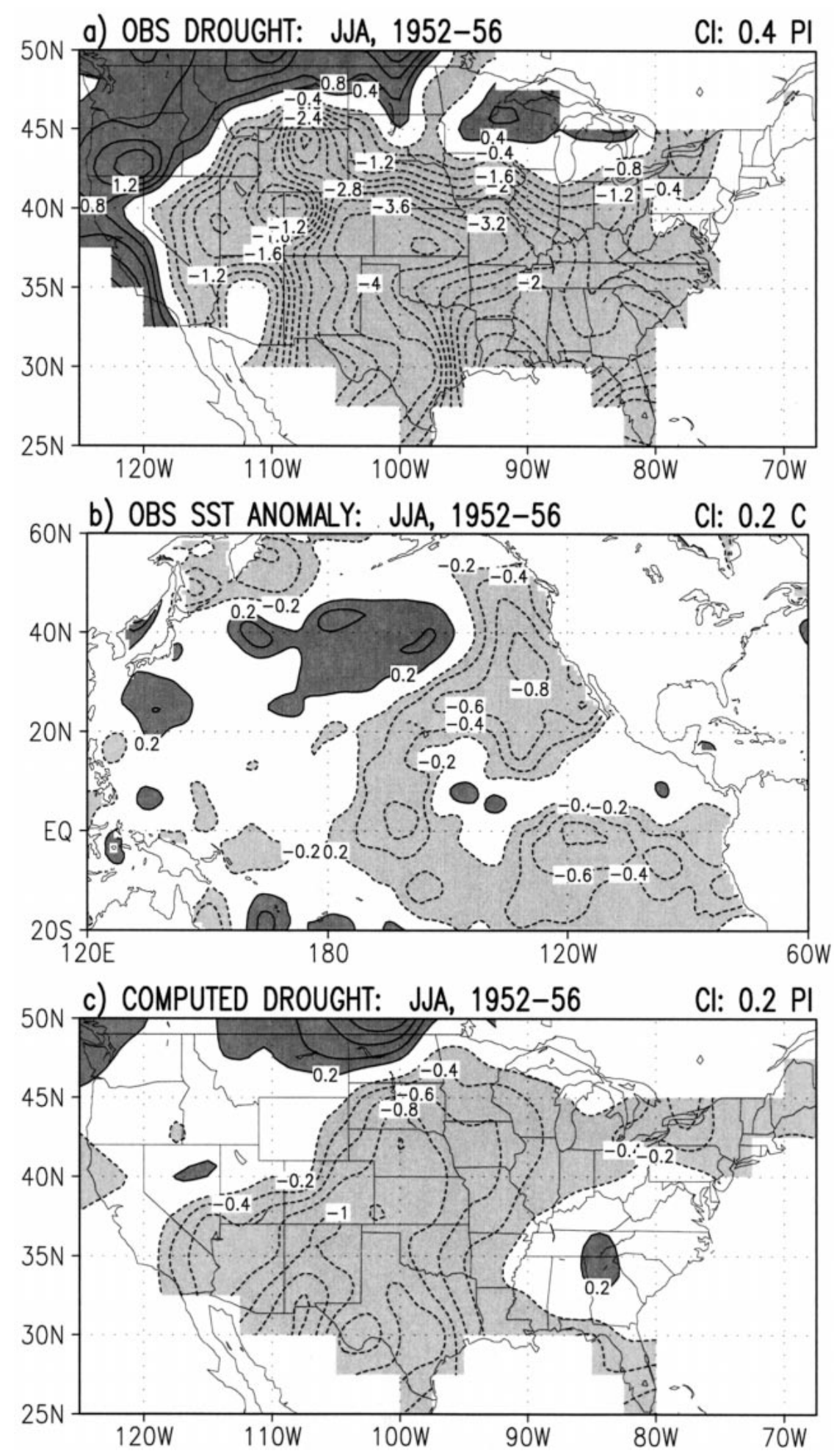

FIG. 8. The observed PDSI averaged during Jun-Aug of 1952-56 is shown in (a), while the corresponding period SST anomalies are shown in (b). The drought signal computed using the SST-drought relationships is shown in (c), using half the contour interval in (a). 

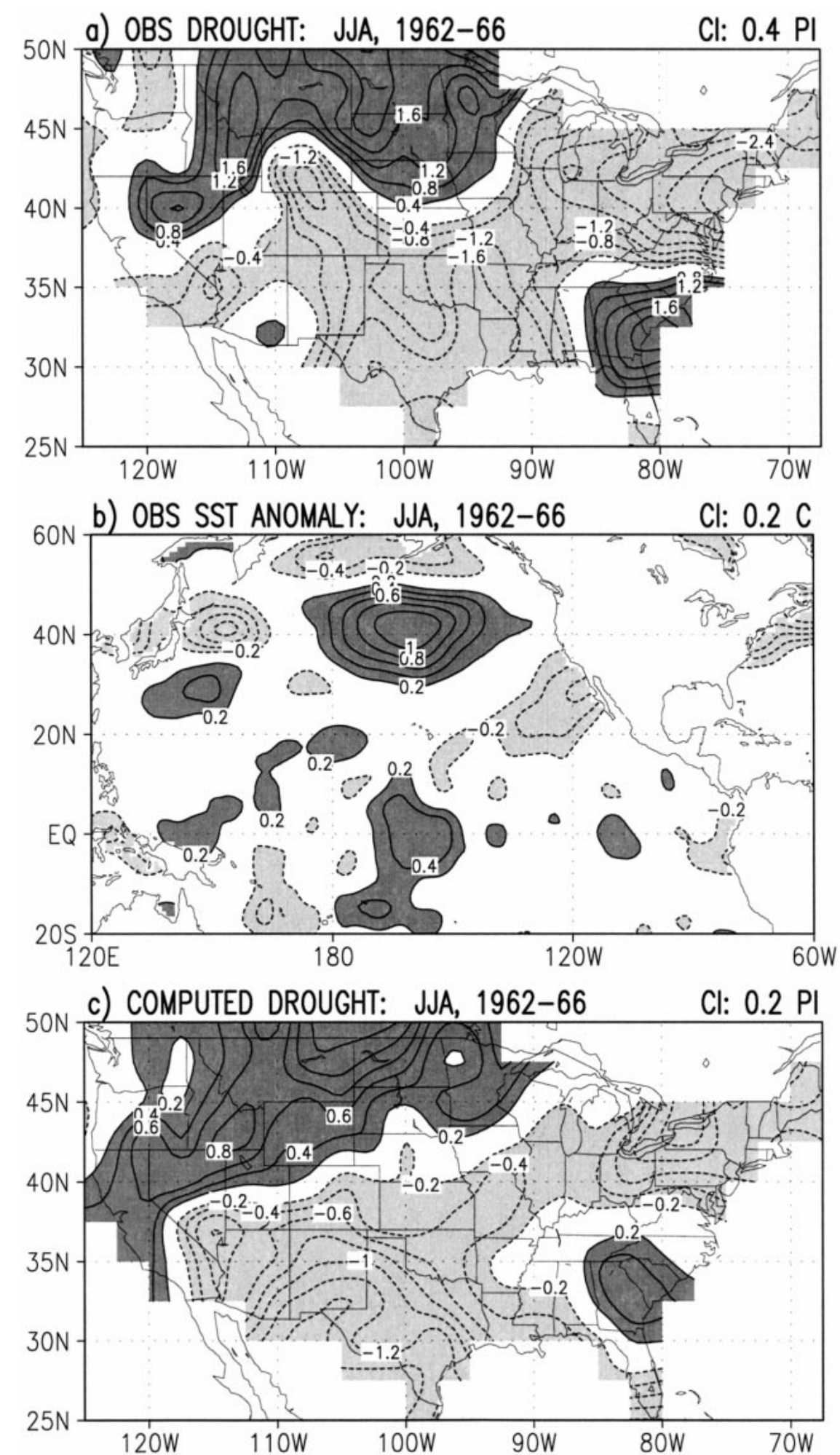

FIG. 9. The observed PDSI averaged during Jun-Aug of 1962-66 is shown in (a), while the corresponding period SST anomalies are shown in (b). The drought signal computed using the SST-drought relationships is shown in (c) using half the contour interval in (a). 

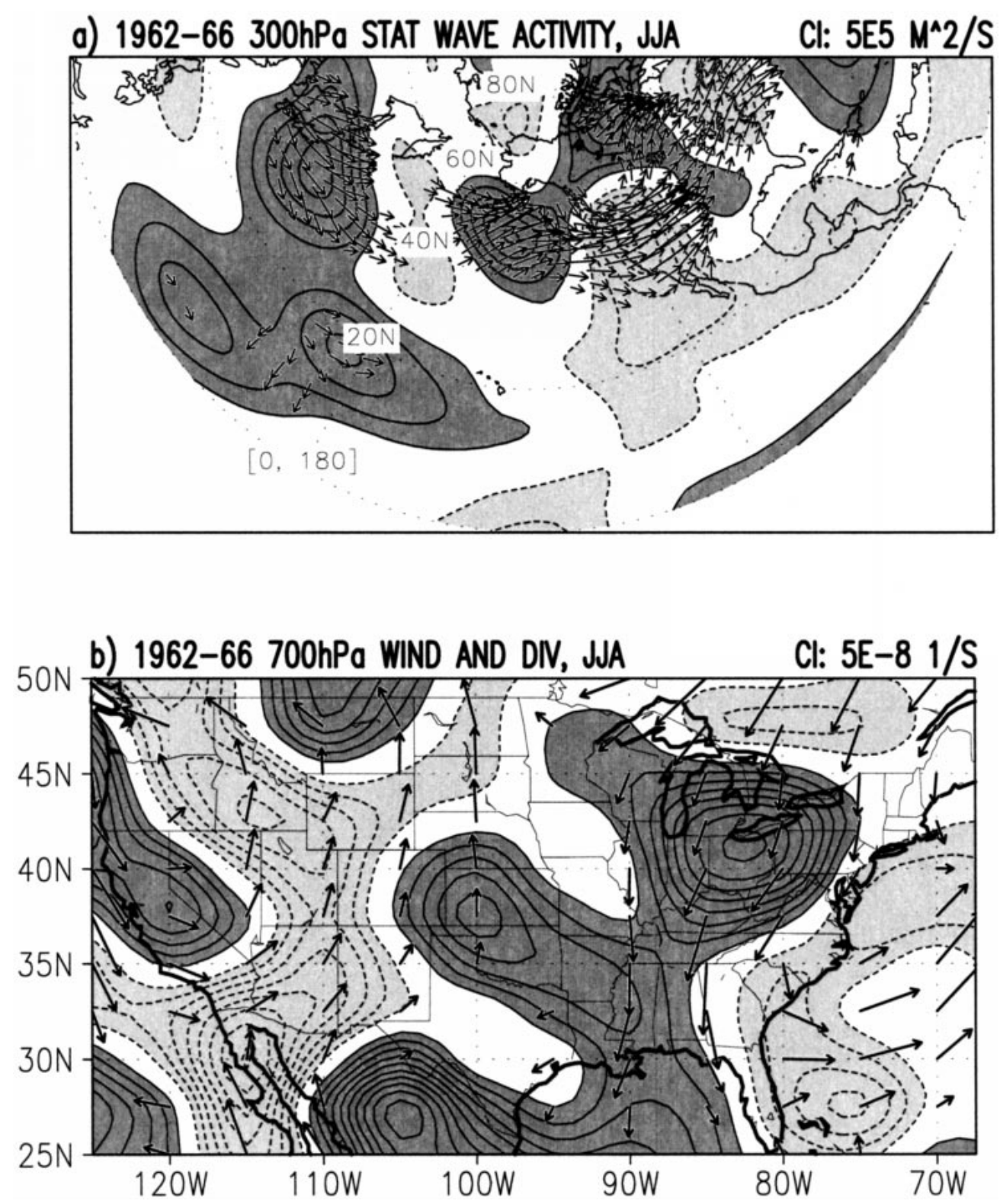

FIG. 10. Horizontal stationary wave activity flux vectors and 300-hPa streamfunction (zonal mean removed) for Jun-Aug, averaged 1962-66, at $300 \mathrm{hPa}$ is shown in (a). The corresponding 700-hPa vector winds and divergence are shown in (b). Note that the vectors in (a) represent stationary wave activity, whereas the vectors in (b) represent the horizontal wind.

the pattern of observed SST anomalies, the North Pacific mode is dominant during this period, so the SST-related drought pattern looks very similar to the general North Pacific mode drought relationship (Fig. 4c). This North Pacific mode-related pattern strongly resembles the observed anomalies. Recalculating the general drought relationship for the North Pacific mode without the 1960s, to avoid bias towards this single event, results in a weaker signal but with the same general features, including the negative maxima in Texas and the Northeast. Thus, the correspondence between observed 1960s drought and the general drought relationship with the North $\mathrm{Pa}$ cific mode is reasonably robust.

Because the NCEP-NCAR reanalysis begins in 1958, the observed circulation anomalies may be examined. Figure 10a shows the $300-\mathrm{hPa}$ streamfunction anomalies, zonal mean removed, and the associated stationary wave activity for June-August, 1962-66. Although the field is somewhat noisy, as expected from a simple time average, a coherent flux of wave activity extends from the eastern North Pacific across the United States, associated with a series of streamfunction centers of ac- 
tion. The lower-level winds and divergence over the United States are shown in Fig. 10b. (700 hPa is chosen to avoid intersection with the Rockies; the same features in the east may be observed at $925 \mathrm{hPa}$.) The upperlevel cyclone-ridge-cyclone pattern is reflected in the lower levels. This near-equivalent-barotropic character is consistent with remote forcing. The cyclonic circulation over the eastern United States opposes the climatological summertime inflow of moisture into the eastern United States, which is associated with the western extension of the Bermuda high and consistent with the band of drought from Texas to the Northeast. This is as in the general relationship (Fig 7c), but with much greater strength over the Northeast. The eastern extent of the cyclonic circulation over the western United States is consistent with a strengthening of the largescale flow in the northern regions of the central United States, which may explain the wet anomalies in the north-central regions during this period, perhaps at the expense of the regions directly to the south.

There is a consistent picture, then, physically linking the North Pacific SST anomalies with the drought: a local atmospheric anomaly develops in association with the SST anomalies; in turn, a flux of stationary wave activity develops, extending over the United States, and the equivalent-barotropic cyclonic circulation over the Northeast opposes the normal influx of moisture.

The primary question, then, is why the drought occurred in 1962-66, since the North Pacific mode has been active, in the positive phase, during other times (see Fig. 3c) without severe drought; several possibilities exist. Notable SST anomalies are also present in the Atlantic Ocean adjacent to the northeastern drought area, as noted by Namias (1966, 1967), who suggested that positive feedback between the local Atlantic SST and circulation anomalies contributed to the persistence of this drought. Consistent with this, the general stationary wave activity associated with the North Pacific mode (Fig. 7c) extends only weakly into the Northeast, whereas the observed activity during the drought extends strongly into the Northeast. The negative SST anomalies off the northeastern coast are accompanied by positive anomalies off the southern coast of Greenland throughout the drought episode, forming a dipole structure. An index of this Atlantic dipole shows considerable correlation to drought in the Northeast and is also consistent with a local, reinforcing role for the Atlantic. The dipole structure is reminiscent of the SST signature of the North Atlantic oscillation (NAO; Rodwell et al. 1999) and, indeed, the November-February average of the Climate Prediction Center's NAO index shows $1963-66$ to be a coherent period (in the seasonal average) of negative NAO activity (Halpert and Bell 1997, their Fig. 31).

Another possibility is that the atmospheric connection to the SST mode may be interfered with by other activity; the 1962-66 period is an unusually coherent episode of the North Pacific mode, with relatively little other SST signal. The uniqueness of the period in the North Pacific, difficult to see in the evolution of SST index, is highlighted in the subsurface temperature anomalies, which are shown averaged over the region of the North Pacific mode in Fig. 11 (data unavailable for 1945-50). The 1962-66 period is seen to be the dominant period of positive subsurface anomalies. The strong negative anomalies in the late 1970s and 1980s have been examined by Deser et al. (1996), who showed that the lower-frequency variations are the result of a series of high-frequency pulses, apparently propagating down from the surface. The warm anomalies in the 1960s are also composed of a series of pulses, although the propagation and apparent wintertime forcing of the Deser et al. study is not prominent (possibly due to the greater data scarcity of this earlier period). In fact, the SST anomalies are greatest in summer, when the atmospheric forcing is weakest. The summertime maximum in the variability of the North Pacific mode has also been noted by Zhang et al. (1998), and the possibility of a role for low clouds in maintaining the summertime SST anomalies, despite the shallow mixed layer, has been explored by Norris et al. (1998). The current analysis highlights the importance of the subsurface variability in understanding the North Pacific mode and the uniqueness of the 1960s, although the uncertainties in the data assimilation during this data-scarce period must be carefully examined.

\section{Sensitivity analysis of SST modes}

\section{a. Verification of modes in 1900-91 data}

For decadal-scale variability, the $1945-93$ period provides only a small number of possible realizations. In order to verify that analysis based on this relatively short period does not distort the structure of low-frequency variability, the SST analysis was also performed on the 1900-91 period, from the Kaplan et al. (1998) SST data. The northern extent of the domain was restricted to $50^{\circ} \mathrm{N}$ to avoid a region of high variance and low data coverage. Six modes were rotated (rotation of nine modes produced similar results, but six modes produced the closest correspondence, probably because the longerterm data were more sensitive to larger numbers of rotated modes). The grid was latitude-weighted to avoid bias due to the unequal areas of a latitude-longitude grid; this is comparable to the equal-area grid used for the short-term data (see Chung and Nigam 1999). Modes corresponding to the PDO and the North Pacific mode were second and fourth, respectively, in terms of variance explained; the time variations are shown in Fig. 12, filled in line form, with the shorter term analysis overlaid. The agreement is good (correlations of 0.96 , 0.80 , and 0.89 , respectively), particularly in the lower frequencies, and, correspondingly, the spatial patterns (not shown) are quite similar, as well. We have also verified that the drought relationships, as computed from 

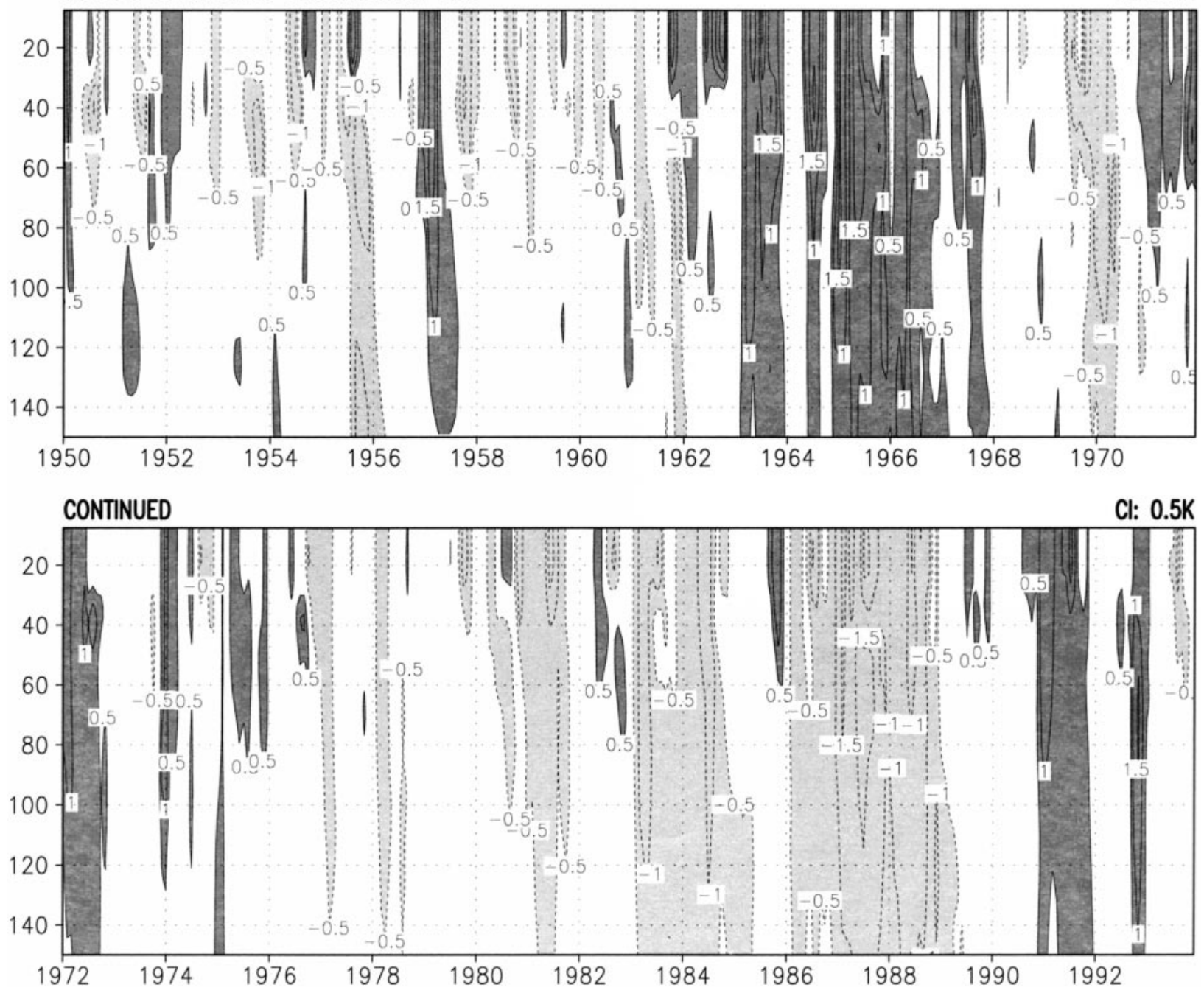

FIG. 11. The subsurface ocean temperature anomalies, averaged over the region of the North Pacific mode, are shown for (top) 1950-71 and (bottom) 1972-73 (data unavailable for 1945-50).

the 1945-91 portion of the long-term analysis, are quite similar to those shown from the short-term analysis (cf. Fig. 4). The third and fourth modes of the long-term analysis correspond to the fourth and fifth modes of the short-term analysis, with good agreement during the mutual time period, also. The same analysis technique was applied to the Kaplan et al. (1998) data for the nonoverlapping 1900-44 period, again yielding the same modes and further verifying the stability of the spatial and temporal structures of the modes.

The long-term analysis also shows that the general features of the variability seen for each mode in the short term are present in the long term as well. In particular, note that the dramatic shift in the PDO in 197677 is not unprecedented in the long term. While the data coverage in the Pacific is rather poor before 1945, and therefore not definitive, the longer analysis does yield very consistent results. This general agreement in spatial structure, temporal structure, and drought relationship strongly suggests that the relative shortness of the 194593 period is not materially affecting the extraction of the decadal-scale variability, as far as can be determined from the existing observational data.

\section{b. Comparison with regional and unrotated analyses}

As noted in section 3, there are some significant differences between the PDO derived in this study and variants derived previously. Previous analysis has almost exclusively involved unrotated EOF-principle component-type analysis. The lack of rotation imposes a rather strict constraint: all modes must be spatially orthogonal. As demonstrated by Richman (1986), this approach can be prone to producing nonphysical modes.

An example of the analysis in this study, but performed in a more regional domain and without rotation, 

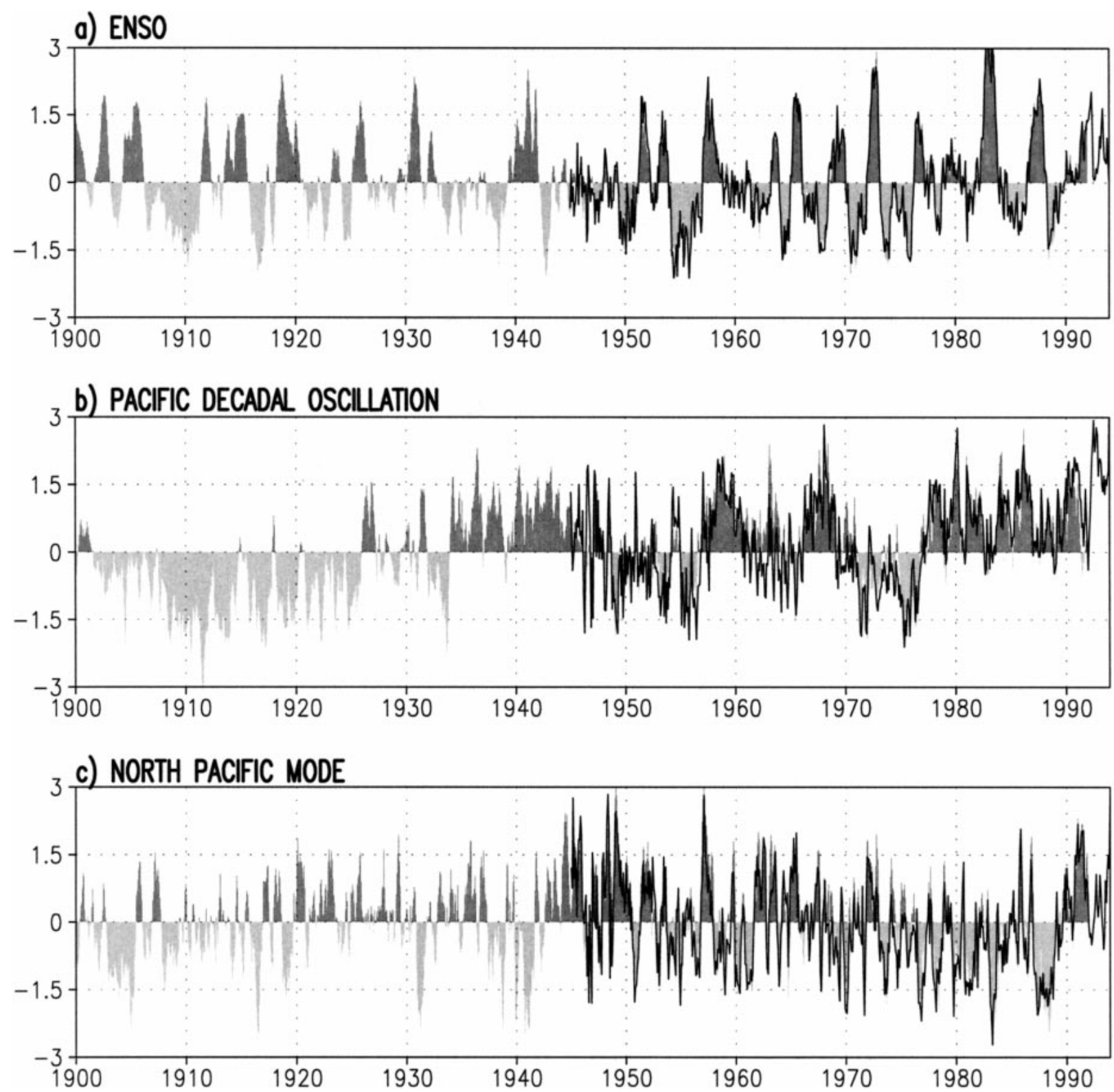

FIG. 12. The shaded curves are the principal components (time series) for the three SST modes as derived from the 1900-91 Kaplan et al. (1998) data: (a) ENSO, (b) Pacific decadal, and (c) North Pacific. The superimposed lines are the respective values from the base analysis (in Fig. 2).

is shown in Fig. 13a. The rectangle in the North Pacific delineates the analysis area; the resulting time series is then regressed to SSTs throughout the full domain to show the associated large-scale pattern. This approach is like that of Mantua et al. (1997), with similar results. In particular, the resultant first mode is similar to the PDO of this study (Fig. 2b), but with substantially more signal in the North Pacific and in the eastern equatorial Pacific. In fact, this mode looks like a mix of the PDO and the North Pacific from the current study. As previously noted, unrotated analysis cannot yield two modes that are not spatially orthogonal, and these two modes are not. This means that unrotated analysis is unable to extract both the PDO and North Pacific modes as realized in this study. ${ }^{5}$ Since the North Pacific mode

\footnotetext{
${ }^{5}$ Nakamura et al. (1997) derive two decadal modes with similarity to the PDO and the North Pacific mode from unrotated analysis. But note that in their analysis there is no overlap between the two extracted modes in the analysis domain. This may be due to their even smaller domain; heavily filtered, reconstructed data; or focus on the winter season. Note, however, that when the spatial orthogonality restraint is relaxed, the full domain is used, and all months are in-
} 
a) 1ST UNROT MODE, SMALL DOMAIN

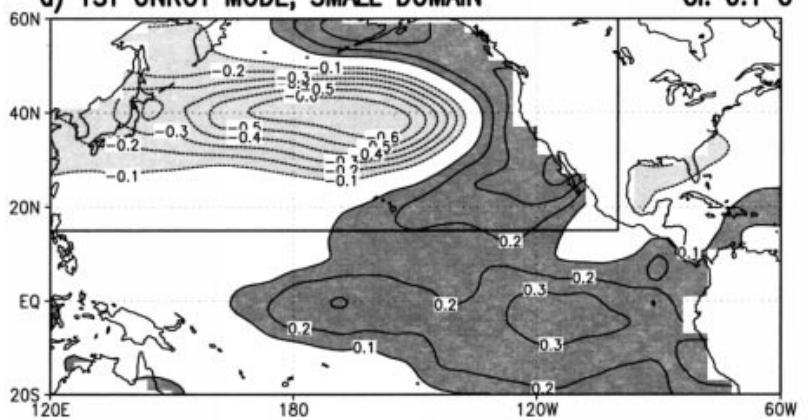

c) 2ND ROT MODE, SMALL DOMAIN

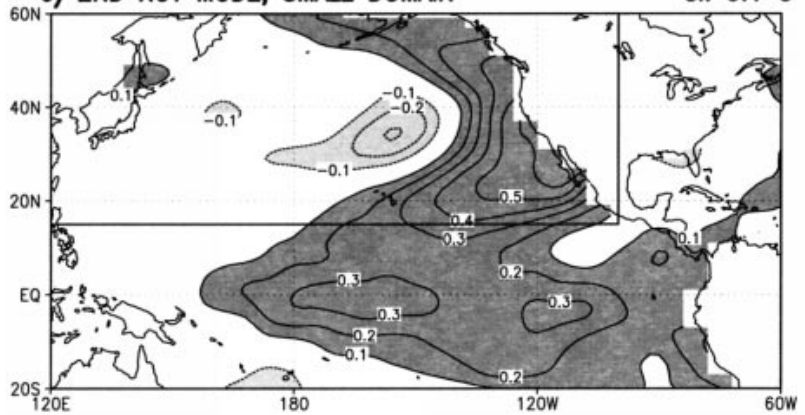

b) 1ST ROT MODE, SMALL DOMAIN

Cl: $0.1 \mathrm{C}$

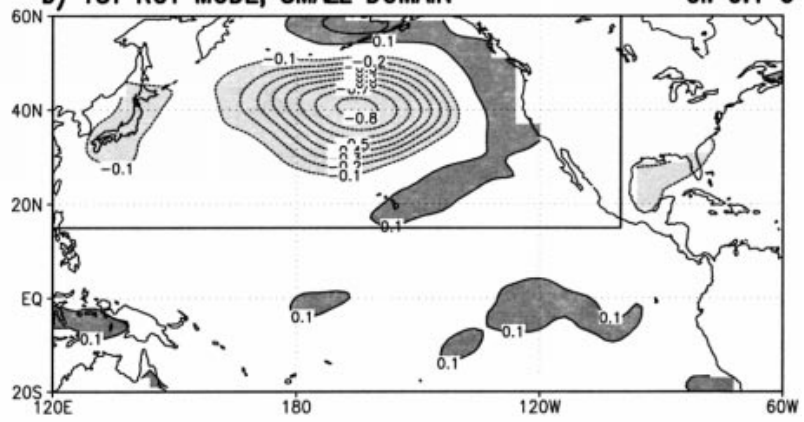

d) 1ST UNROT MODE, FULL DOMAIN

Cl: $0.1 \mathrm{C}$

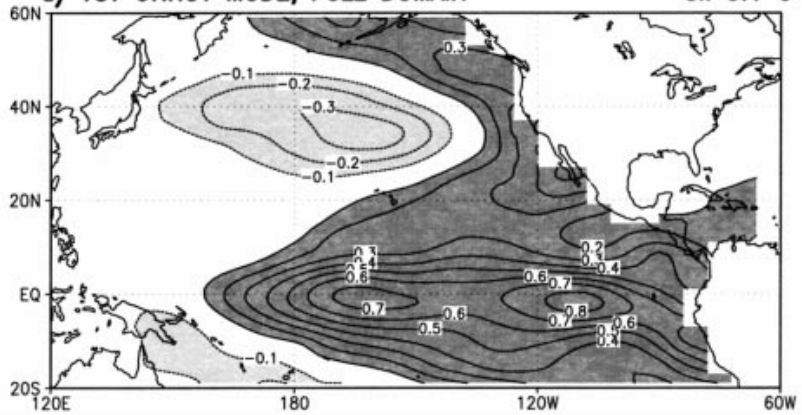

FIG. 13. The spatial pattern for the leading unrotated mode of SST variability in the North Pacific is shown in (a), with the domain region indicated by the inner rectangle. Values outside the analysis domain were obtained by regression to the time series. The first two rotated modes for the same analysis region are shown in (b) and (c). The first unrotated mode for the full domain is shown in (d).

has been identified in several previous analyses, as noted in the introduction, and since it is physically realized in the data (e.g., in the 1960s), it seems most likely that there are indeed two distinct physical modes, but that an unrotated analysis will mix them together. If the regional analysis is then rotated, it yields, as the first two modes, a North Pacific mode (Fig. 13b) and a PDO mode (Fig. 13c) that are quite similar to those of the current studies. The remaining differences are due to the regional analysis, which analyzes the PDO based on only part of its structure and, additionally, biases in ENSO, which has a somewhat similar structure in the North Pacific.

Finally, we note that rotation is an issue even for the first mode of a full domain analysis. Figure 13d shows the first unrotated mode for the full domain. It is quite similar to the ENSO mode (Fig. 1a) and is very highly correlated, but has some spatial differences that are distracting. Note that, in this unrotated realization (which cannot accurately resolve the PDO, because it is not orthogonal to ENSO), ENSO has more signals in the North Pacific and begins to look more similar to the PDO. Additionally, the time series (not shown) begins to show something like the 1976/77 transition of the PDO, further confusing the issue.

cluded, as in the current study, the two modes do overlap significantly, and thus cannot be resolved in unrotated analysis.
Given that two of the three modes span the larger domain, and that unrotated analysis is unable to resolve the three modes together, we strongly advocate largedomain, rotated analysis.

\section{Summary and discussion}

The connection between Pacific Ocean variability and U.S. hydroclimate is investigated by extracting the three primary modes of Pacific SST variability and documenting the relationships with U.S. precipitation, drought, and stream flow. Both the general relationships and specific long-term U.S. drought episodes are considered. The atmospheric linkage between the Pacific and the United States is examined in the streamfunction field, and the coherence and propagation direction of the associated stationary wave activity is assessed.

The modes of Pacific variability are extracted via rotated principal component analysis for the full Pacific domain north of $20^{\circ} \mathrm{S}$. This technique extracts the three primary modes from a single analysis, allowing a direct intercomparison of the structures, as well as an unambiguous partitioning of explained variance.

Following are the principal findings of this study.

- There is a significant relationship between the three primary modes of Pacific variability (ENSO, PDO, and the North Pacific mode) and U.S. warm season precipitation, drought, and stream flow. The relationships with drought and stream flow vary little through- 
out the season, but the relationship with precipitation varies substantially from month to month.

- All three SST modes are associated with a coherent flux of stationary wave activity over the North Pacific that propagates into the United States. The atmospheric anomalies are for the most part equivalent barotropic in structure and consistent with the largescale patterns in the hydrologic signal.

- The SST modes are also related to specific, long-term U.S. drought episodes. Most notably, the northeastern drought of 1962-66 is closely associated with the North Pacific mode. This period also provides an example of a physical expression of the mode, further validating the modal SST analysis.

- The PDO and the North Pacific mode represent two distinct modes with decadal signal in the North Pacific, with the North Pacific mode capturing most of the local variability. The North Pacific mode also includes notable high-frequency variability. In the subsurface temperature data, the high-frequency variations take the form of pulses, while the low-frequency variations appear as a modulation of these pulses. The notable changes in the Pacific Ocean, centered on $1976 / 77$, are well captured by the evolution of the PDO.

Since there is a heavy socioeconomic cost associated with drought, particularly the severe, long-term droughts of the 1950s and 1960s, it is of considerable interest to assess the predictive capabilities inherent in the present analysis. While the identified relationships do not have inconsequential magnitudes, the best-case scenario based on the simultaneous, linear relationships, as given, would probably not explain more than $25 \%$ of the variance for most regions.

The current analysis, however, is not necessarily intended to be directly applied to prediction but rather to identify the important variability structures for further study. In particular, a critical issue is the identification of the factors that cause the general precursor relationships to greatly intensify during particular periods (e.g., 1962-66). A natural next step is a case study, focusing on the development of the anomalous conditions into the mature structures documented in the current study. Given the new availability of three-dimensional information in both the atmosphere and the ocean during the 1962-66 period, a detailed analysis of this drought episode can now be undertaken. Hopefully, a monthly analysis of the codevelopment of the oceanic and atmospheric anomalies will shed some light on the dynamics of the variability, particularly of the subsurface pulses in the North Pacific. As part of an analysis of the evolution of the pattern, the summertime hydrologic analysis of this study needs to be extended to the other seasons, particularly winter, when large storage terms can be set up through snowpack.

The relationship between U.S. hydroclimate and other modes of SST variability, such as the second mode in
Ting and Wang (1997) and the various Atlantic modes, particularly the NAO, also needs to be further examined, particularly with respect to possible coupled effects with the three Pacific modes considered here.

Finally, the structure of the SST modes needs further analysis. This study highlights two features of the modes that need to be further developed: the vigor of the decadal variability in summer, when atmospheric forcing is relatively weak; and the broad range of frequencies associated with the "decadal" modes, particularly the subsurface pulses that apparently link the high and low frequencies of the North Pacific mode.

Acknowledgments. We thank Eugene Rasmusson for helpful discussions and Harry Lins for providing us the Hydro-Climatic Data Network datasets and for a careful review of the manuscript. Comments by three anonymous reviewers considerably improved the original manuscript. This research was supported by the National Oceanic and Atmospheric Administration's Pan American Climate Dynamics program (Grant NA76GP0479) and by the National Science Foundation's Climate Dynamics program (Grant ATM-9422507). Mathew Barlow is a UCAR postdoctoral fellow at IRI.

\section{REFERENCES}

Alley, W., 1984: The Palmer Drought Severity Index: Limitations and assumptions. J. Climate Appl. Meteor., 23, 1100-1109.

Barlow, M., S. Nigam, and E. Berbery, 1998: Evolution of the North American monsoon system. J. Climate, 11, 2238-2257.

Bottomley, M., C. K. Folland, J. Hsiung, R. E. Newell, and D. E. Parker, 1990: Global Ocean Surface Temperature Atlas. United Kingdom Meteorological Office and Massachusetts Institute of Technology $20 \mathrm{pp}$. and 313 plates.

Carton, J., G. Chepurin, X. Cao, and B. Giese, 1999a: A simple ocean data assimilation analysis of the global upper ocean 1950-95. Part I: Methodology. J. Phys. Oceanogr., 30, 294-309.

$\longrightarrow,-$, and $-1999 \mathrm{~b}$ : A simple ocean data assimilation analysis of the global upper ocean 1950-95. Part II: Results. J. Phys. Oceanogr., 30, 311-326.

Cayan, D., and R. H. Webb, 1992: El Niño/Southern Oscillation and streamflow in the western U.S. Historical and Paleoclimatic Aspects of the Southern Oscillation, H. F. Diaz and V. Markgraf, Eds., Cambridge University Press, 29-68.

—, M. Dettinger, H. Diaz, and N. Graham, 1998: Decadal variability of precipitation over western North America. J. Climate, 11, 3148-3166.

Chung, C., and S. Nigam, 1999: Weighting of geophysical data in principal component analysis. J. Geophys. Res., 104, $16925-$ 16928.

Cressman, G., 1959: An operational objective analysis system. Mon. Wea. Rev., 87, 367-374.

da Silva, A., C. Young, and S. Levitus, 1994: Algorithms and Procedures. Vol. 1, Atlas of Surface Marine Data 1994, NOAA Atlas NESDIS 6, U.S. Department of Commerce, 83 pp.

Davis, R., 1976: Predictability of sea surface temperature and sea level pressure anomalies over the North Pacific Ocean. J. Phys. Oceanogr., 6, 249-266.

Deser, C., and M. Blackmon, 1995: On the relationship between tropical and North Pacific sea surface temperature variations. J. Climate, 8, 1677-1680.

_ M. A. Alexander, and M. S. Timlin, 1996: Upper-ocean thermal variations in the North Pacific during 1970-1991. J. Climate, 9, $1840-1855$. 
Diaz, H., 1983: Drought in the United States-Some aspects of major dry and wet periods in the contiguous United States, 1895-1981. J. Climate Appl. Meteor., 22, 3-16.

Douglas, A., and P. Englehart, 1981: On a statistical relationship between autumn rainfall in the central equatorial Pacific and subsequent winter precipitation in Florida. Mon. Wea. Rev., 109, 2377-2382.

Enfield, D., and A. Mestas-Nuñez, 1999: Multiscale variabilities in global sea surface temperatures and their relationships with tropospheric climate patterns. J. Climate, 12, 2719-2733.

Folland, C. K., and D. E. Parker, 1995: Correction of instrumental biases in historical sea surface temperature data. Quart. J. Roy. Meteor. Soc., 121, 319-367.

Frankignoul, C., and K. Hasselmann, 1977: Stochastic climate models, II. Application to sea-surface temperature variability and thermocline variability. Tellus, 29, 284-305.

Gershunov, A., and T. Barnett, 1998: ENSO influence on intraseasonal extreme rainfall and temperature frequencies in the contiguous United States: Observations and mode results. J. Climate, 11, $1575-1586$.

Gill, A., 1980: Some simple solutions for heat-induced tropical circulation. Quart. J. Roy. Meteor. Soc., 106, 447-462.

Halpert, M., and C. Ropelewski, 1992: Surface temperature patterns associated with the Southern Oscillation. J. Climate, 5, 577-593.

— Meteor. Soc., 78, S1-S49.

Hasselmann, K., 1976: Stochastic climate models. Part I. Theory. Tellus, 28, 289-305.

Higgins, R., Y. Chen, and A. Douglas, 1999: Interannual variability of the North American warm season precipitation regime. $J$. Climate, 12, 653-680.

Hoerling, M., A. Kumar, and M. Zhong, 1997: El Niño, La Niña, and the nonlinearity of their teleconnections. J. Climate, 10, 17691786 .

Kalnay, E., and Coauthors, 1996: The NCEP/NCAR 40-year Reanalysis Project. Bull. Amer. Meteor. Soc., 77, 437-471.

Kaplan, A., M. Cane, Y. Kushnir, and M. Blumenthal, 1997: Reduced space optimal analysis for historical data sets: 136 year of Atlantic sea surface temperatures. J. Geophys. Res., 102, 27 83527860 .

,,--- A. Clement, M. Blumenthal, and B. Rajagopalan, 1998: Analyses of global sea surface temperature 1856-1991. J. Geophys. Res., 103, 18 567-18 589.

Karl, T., and A. Koscielny, 1982: Drought in the United States: 18951981. J. Climatol., 2, 313-329.

_ , and C. Williams Jr., 1987: An approach to adjusting climatological time series for discontinuous inhomogeneities. J. Climate Appl. Meteor., 26, 1744-1763.

$\longrightarrow, \ldots$, F. Quinlan, and T. Boden, 1990: United States Historica Climatology Network $(\mathrm{HCN})$ serial temperature and precipitation data. Environmental Science Division, Publication 3404 389 pp. [Available from Carbon Dioxide Information and Analysis Center, Oak Ridge National Laboratory, Oak Ridge, TN 37831.]

Karoly, D., R. A. Plumb, and M. Ting, 1989: Examples of the horizontal propagation of quasi-stationary waves. J. Atmos. Sci., 46, 2802-2811.

Kushnir, Y., and N.-C. Lau, 1992: The general circulation model response to a North Pacific SST anomaly: Dependence on time scale and pattern polarity. J. Climate, 5, 271-283.

Levitus, S., 1982: Climatological Atlas of the World Ocean, NOAA Prof. Paper No. 13, 173 pp. and 17 microfiche.

_- T. Boyer, 1994: Temperature, Vol. 4, World Ocean Atlas 1994, NOAA Atlas NESDIS, $117 \mathrm{pp}$.

— 1994, NOAA Atlas NESDIS, 99 pp.

Lins, H., 1997: Regional streamflow regimes and hydroclimatology of the United States. Water Resour. Res., 33, 1655-1667.

Livezey, R., and W. Chen, 1983: Statistical field significance and its determination by Monte Carlo techniques. Mon. Wea. Rev., 111, $46-59$.

_ and T. Smith, 1999: Covariability of aspects of North American climate with global sea surface temperatures on interannual to interdecadal timescales. J. Climate, 12, 289-302.

Lyon, B., and R. Dole, 1995: A diagnostic comparison of the 1980 and 1988 U.S. summer heat wave-droughts. J. Climate, 8, $1658-$ 1675 .

Madden, R., 1999: Aliasing in the spectrum of time-averaged data. Proc. Eighth Conf. on Climate Variations, Denver, CO, Amer. Meteor. Soc., 229-230.

Mantua, N., S. Hare, Y. Zhang, J. M. Wallace, and R. Francis, 1997: A Pacific interdecadal climate oscillation with impacts on salmon production. Bull. Amer. Meteor. Soc., 78, 1069-1079.

Mestas-Nuñez, A., and D. Enfield, 1999: Rotated global modes of non-ENSO sea surface temperature variability. J. Climate, 12, 2734-2746.

Montroy, D., 1997: Linear relation of central and eastern North American precipitation to tropical Pacific sea surface temperature anomalies. J. Climate, 10, 541-558.

_- M. Richman, and P. Lamb, 1998: Observed nonlinearities of monthly teleconnections between tropical Pacific sea surface temperature anomalies and central and eastern North American precipitation. J. Climate, 11, 1812-1835.

Nakamura, H., G. Lin, and T. Yamagata, 1997: Decadal climate variability in the North Pacific during the recent decades. Bull. Amer. Meteor. Soc., 78, 2215-2225.

Namias, J., 1966: Nature and possible causes of the northeastern United States drought during 1962-65. Mon. Wea. Rev., 94, 543554.

1967: Further studies of drought over northeastern United States. Mon. Wea. Rev., 95, 497-508.

Newman, M., and P. Sardeshmukh, 1998: The impact of the annual cycle on the North Pacific/North American response to remote low-frequency forcing. J. Atmos. Sci., 55, 1336-1353.

Nigam, S., and H.-S. Shen, 1993: Structure of oceanic and atmospheric low-frequency variability over the tropical Pacific and Indian Oceans. Part I: COADS observations. J. Climate, 6, 657676.

Nitta, T., and S. Yamada, 1989: Recent warming of tropical sea surface temperature and its relationship to the Northern Hemisphere circulation. J. Meteor. Soc. Japan, 67, 375-383.

Norris, J., Y. Zhang, and J. Wallace, 1998: Role of low clouds in summertime atmosphere-ocean interactions over the North Pacific. J. Climate, 11, 2482-2490.

Palmer, W. C., 1965: Meteorological drought. U.S. Weather Bureau Tech. Paper 45, 58 pp. [Available from NOAA/National Weather Service, 1325 East-West Highway, Silver Spring, MD 20910.]

Parker, D. E., P. D. Jones, C. K. Folland, and A. Bevan, 1994: Interdecadal changes of surface temperature since the late nineteenth century. J. Geophys. Res., 99, 14 373-14 399.

Piechota, T., and J. Dracup, 1996: Drought and regional hydrologic variation in the United States: Associations with the El NiñoSouthern Oscillation. Water Resour. Res., 32, 1359-1373.

Plumb, R., 1985: On the three-dimensional propagation of stationary waves. J. Atmos. Sci., 42, 217-229.

Rasmusson, E., 1991: Observational aspects of ENSO cycle teleconnections. Teleconnections Linking Worldwide Climate Anomalies, M. H. Glantz, R. W. Katz, and N. Nichols, Eds., Cambridge University Press, 309-343.

— perature and surface wind fields associated with the Southern Oscillation-El Niño. Mon. Wea. Rev., 110, 354-384.

Redmond, K., and R. Koch, 1991: Surface climate and streamflow variability in the western United States and their relationship to large-scale circulation indices. Water Resour. Res., 27, 23812399.

Reynolds, R. W., and T. M. Smith, 1994: Improved global sea surface temperature analysis using optimum interpolation. J. Climate, 7, 929-948. 
Richman, M. B., 1986: Rotation of principal components. J. Climatol., 6, 293-335.

_ P. Lamb, and J. Angel, 1991: Relationships between monthly precipitation over central and eastern North America and the Southern Oscillation. Proc. Fifth Conf. on Climate Variations, Denver, CO, Amer. Meteor. Soc., 151-158.

Rodwell, M., D. Rowell, and C. Folland, 1999: Oceanic forcing of the wintertime North Atlantic Oscillation and European climate. Nature, 398, 320-323.

Ropelewski, C., and M. Halpert, 1986: North American precipitation and temperature patterns associated with the El Niño/Southern Oscillation (ENSO). Mon. Wea. Rev., 114, 2352-2362.

Slack, J. R., and J. M. Landwehr, 1992: Hydro-Climatic Data Network (HCDN): A U.S. Geological Survey streamflow data set for the United States for the study of climate variations, 1874-1988. U.S. Geological Survey Open-File Rep. 92-129, 200 pp. [Available from U.S. Geological Survey, Books and Open-File Reports Section, Federal Ctr., Box 25286, Denver, CO 80225.]

Tanimoto, Y., N. Iwasaka, K. Hanawa, and Y. Toba, 1993: Characteristic variations of sea surface temperature with multiple time scales in the North Pacific. J. Climate, 6, 1153-1160.

Ting, M., and H. Wang, 1997: Summertime U.S. precipitation variability and its relation to Pacific sea surface temperature. J. Climate, 10, 1853-1873.

Trenberth, K., 1990: Recent observed interdecadal climate changes in the Northern Hemisphere. Bull. Amer. Meteor. Soc., 71, 988993.

Vose, R., R. Schmoyer, P. Steurer, T. Peterson, R. Heim, T. Karl, and J. Eischeid, 1992: The Global Historical Climatology Network: Long-term monthly temperature, precipitation, sea level pressure, and station pressure data. Carbon Dioxide Information Analysis Center Rep. 3912, 189 pp. [Available from National Technical Information Service, 5285 Port Royal Rd., Springfield, VA 22161.]

Wallace, J. M., and D. S. Gutzler, 1981: Teleconnections in the geopotential height field during the Northern Hemisphere winter. Mon. Wea. Rev., 109, 784-812.

Weare, B., A Navato, and R. Newell, 1976: Empirical orthogonal analysis of Pacific sea surface temperatures. J. Phys. Oceanogr., 6, 671-678

Wilks, D. S., 1995: Statistical Methods in the Atmospheric Sciences. Academic Press, 467 pp.

Zhang, Y., J. M. Wallace, and N. Iwasaka, 1996: Is climate variability over the North Pacific a linear response to ENSO? J. Climate, 9, 1468-1478.

$\longrightarrow,-$, and D. Battisti, 1997: ENSO-like interdecadal variability: 1900-93. J. Climate, 10, 1004-1020.

- J. Norris, and J. Wallace, 1998: Seasonality of large-scale atmosphere-ocean interaction over the North Pacific. J. Climate, 11, 2473-2481. 